\title{
2-DE Mapping of the Blue Mussel Gill Proteome: The Usual Suspects Revisited
}

\author{
Béatrice Rocher ${ }^{1, *}$, Florence Bultelle ${ }^{1}$, Philippe Chan ${ }^{2}$, Frank Le Foll ${ }^{1}$, Julie Letendre ${ }^{1}$, \\ Tiphaine Monsinjon ${ }^{1}$, Stéphanie Olivier ${ }^{1}$, Romain Péden ${ }^{1}$, Agnès Poret ${ }^{1}$, David Vaudry ${ }^{3}$ \\ and Thomas Knigge ${ }^{1}$
}

1 Laboratory of Ecotoxicology_Aquatic Environments, UMR I-02 SEBIO, Le Havre University, 76063 Le Havre, France; E-Mails: florence.bultelle@univ-lehavre.fr (F.B.); frank.lefoll@univ-lehavre.fr (F.L.F.); julie.letendre@hotmail.com (J.L.); tiphaine.monsinjon@univ-lehavre.fr (T.M.); stephanie.olivier@univ-lehavre.fr (S.O.); romain.peden@univ-lehavre.fr (R.P.); agnes.poret@univ-lehavre.fr (A.P.); thomas.knigge@univ-lehavre.fr (T.K.)

2 PISSARO Proteomic Platform, Institute for Research and Innovation in Biomedicine, University of Rouen, 76821 Mont-Saint-Aignan, France; E-Mail: philippe.chan@univ-rouen.fr

3 Neuronal and Neuroendocrine Differentiation and Communication (DC2N), Inserm U982, University of Rouen, 76821 Mont-Saint-Aignan, France; E-Mail: david.vaudry@univ-rouen.fr

* Author to whom correspondence should be addressed; E-Mail: beatrice.rocher@univ-lehavre.fr; Tel.: +33-232-85-9906; Fax: +33-232-74-4505.

Academic Editor: Dr. Jacek R. Wisniewski

Received: 14 August 2014 / Accepted: 4 December 2014 / Published: 12 January 2015

\begin{abstract}
The Blue Mussel (Mytilus edulis, L. 1758) is an ecologically important and commercially relevant bivalve. Because of its ability to bioconcentrate xenobiotics, it is also a widespread sentinel species for environmental pollution, which has been used in ecotoxicological studies for biomarker assessment. Consequently, numerous proteomics studies have been carried out in various research contexts using mussels of the genus Mytilus, which intended to improve our understanding of complex physiological processes related to reproduction, adaptation to physical stressors or shell formation and for biomarker discovery. Differential-display 2-DE proteomics relies on an extensive knowledge of the proteome with as many proteoforms identified as possible. To this end, extensive characterization of proteins was performed in order to increase our knowledge of the Mytilus gill proteome. On average, 700 spots were detected on 2-DE gels by colloidal blue staining, of which 122 different,
\end{abstract}


non-redundant proteins comprising 203 proteoforms could be identified by tandem mass spectrometry. These proteins could be attributed to four major categories: $(i)$ "metabolism", including antioxidant defence and degradation of xenobiotics; (ii) "genetic information processing", comprising transcription and translation as well as folding, sorting, repair and degradation; (iii) "cellular processes", such as cell motility, transport and catabolism; (iv) "environmental information processing", including signal transduction and signalling molecules and interaction. The role of cytoskeleton proteins, energetic metabolism, chaperones/stress proteins, protein trafficking and the proteasome are discussed in the light of the exigencies of the intertidal environment, leading to an enhanced stress response, as well as the structural and physiological particularities of the bivalve gill tissue.

Keywords: 2-DE; mass spectrometry; proteoforms; post-translational modifications; bivalve mollusc; environmental stress; ecotoxicology

\section{Introduction}

Molluscs belong to one of most diverse animal phyla and are a major component of marine ecological communities, comprising about a quarter of the known marine species. Within this clade, filter-feeding bivalves represent one of the dominating benthic life forms with fundamental importance for the marine ecosystem. Bivalves also provide a valuable food source to humans with numerous important fishery and aquaculture species. Consequently, several bivalve species, such as scallops, oysters and mussels are amongst the most studied marine organisms. In spite of this prominence, the mollusc and, specifically, bivalve genome remains poorly studied [1]. This is even more surprising in view of the fact that various mollusc species serve as models for studying neurobiology, biomineralisation, the adaptation to natural stresses of the coastal environments, ocean acidification and climate change as well as marine pollution [2].

Members of the genus Mytilus are used worldwide as sentinels in the biomonitoring of marine pollution (i.e., Mussel Watch Project, Ifremer, France: "Réseau d'Observation de la Contamination Chimique"), on the one hand for their pervasive geographical distribution and, on the other hand, because they are highly tolerant to xenobiotics, which they bioaccumulate into considerable concentrations. As mussels are sessile, attached to a rocky substrate by their byssus threads, they also allow for spatial localisation of marine pollution, reflecting changes in the contamination of the environment from which they originate. These properties make them useful bioindicators of chemical pollution as well as useful models in ecotoxicology [3-6].

Mussels are naturally exposed to fluctuations of numerous abiotic factors, such as oxygen availability, temperature and salinity changes, which follow the rhythms in the intertidal zones [7]. Significant changes of body temperature of more than $20{ }^{\circ} \mathrm{C}$ occur, both when exposed to warm air and/or heated by solar radiation as well as when immersed into cold water afterwards $[8,9]$. Emersion and reimmersion are also accompanied by changes in oxygenation and metabolic activity, leading to oxidative stress [10,11]. Furthermore, blue mussels can cope with wide ranges of salinity allowing them to occupy brackish habitats of the estuaries. Hence, these animals provide an excellent model to study the stress response in dynamically changing environments as well as questions of adaptation to a life in the extremes [12]. The 
variability of stressful conditions is likely to stimulate quantitative changes in many different proteins at any one time [13]. In view of this complexity of interdepending mechanisms of the stress response, a systems biology approach is likely to provide a more comprehensive insight into the underlying molecular regulatory networks. Proteomics may thus capture the complexity of these stress responses better than a battery of individual assays.

Since Mytilus ssp. is cosmopolitan, different species can be found on the shores around the world and their thermal adaptation and oxidative stress response is likely to differ between species according to their distribution range $[9,14,15]$. Climate change is assumed to shift the range limits of the geographical distribution of Mytilus species with the thermal adaption of the congeners mostly determining their ability to invade new regions or to occupy different, i.e., subtidal and intertidal, habitats $[9,16,17]$. Also, where the biogeographic ranges overlap, Mytilus congeners may hybridise, with the hybrids possibly having specific ecophysiological properties. Extensive hybridisation occurs between M. edulis and M. galloprovincialis along the coasts of Western Europe as well as between M. trossulus and M. galloprovincialis in the Baltic sea, along the west coast of North America, in Japan and adjoining coastal areas $[16,18,19]$. As M. galloprovincialis is often outgrowing the native species, it is also considered a problematic invasive species [16,20]. Proteomics has been employed to investigate Mytilus ssp. and to distinguish hybridisation forms [21-23]. Hybridisation also involves mechanisms of doubly uniparental mtDNA inheritance, a particularity of certain bivalve orders, including Mytiloida [19,24]. This phenomenon represents another aspect of Mytilus biology to which proteomics has been applied [24,25].

Although Mytilus spp. is considered a key model organism for molluscan biology [12] and is deemed to be an upcoming model organism [26], proteomics studies using Mytilidae are still hampered by limited knowledge on mussel genes as well as their expression in natural or polluted conditions. Notwithstanding the numerous studies that have focused on proteomic changes in mussels within the contexts outlined above, relatively few protein identifications have been accomplished in regard to the thousands of proteins present in a mussel (reviewed in [14,23,27,28]). In the present study, we intended to expand the description of the mussel gill proteome using gel-based proteomics. Although proteome coverage may be extended by mass-spectrometry based shotgun proteomics, 2-DE remains a valuable top-down proteomics approach [29]. On all accounts, it persists as the most commonly used technique in environmental proteomics. In addition, it may be particularly suited for the identification of both PTMs and protein isoforms as a result of environmental and/or pollution stress, which, however, have been scarcely investigated to date.

In filter-feeding bivalves, the gills are one of the major sites of interaction with the environment [30]. Their ctenidiae consist of lamellae, made up of ciliated filaments that create water currents in the pallial cavity, which are used both for breathing and feeding. Besides the gas exchange over the gill epithelia, the suspended food particles are retained in the gill mucus, sorted and transported by the cilia to the mouth $[17,31]$. Blue mussels can filter up to $5 \mathrm{~L}$ of seawater per hour over a large surface area. Consequently, the bivalve gills are one of the primary organs to be exposed to abiotic stressors such as thermal stress and desiccation as well as oxidative stress. Also, they are one of the major organs to be exposed to pollutants. These properties make them particularly interesting for studying proteomic alterations in relation to environmental and anthropogenic stressors. The findings of the present study will be discussed in light of the structural and functional characteristics of the bivalve gills. 


\section{Experimental Section}

\subsection{Chemicals}

Reagents were purchased from GE Healthcare (Vélizy-Villacoublay, France) except acetonitrile (ACN) and trypsin, which were obtained from Thermo Fisher Scientific (Villebon-sur-Yvette, France) and Promega (Charbonnières, France), respectively. All chemicals used were of the highest grade available.

\subsection{Animals and Sample Preparation}

Adult blue mussels Mytilus edulis (4-5 cm shell length) were collected on the seashore of Yport, France $\left(49^{\circ} 44^{\prime} \mathrm{N} ; 0^{\circ} 18^{\prime} \mathrm{E}\right)$. It was approved by the ethics committee for animal experimentation of Normandy University that the use of bivalves in this study conforms to the European Directive 2010/63/EU concerning the care and use of laboratory animals under the French law on ethics of animal experimentation. The mussels were transported to the laboratory in aerated seawater from the sampling site at the pre-existing temperature. Upon arrival, the mussels were dissected immediately and gills were homogenized mechanically using an electric potter, in $50 \mathrm{mM}$ Tris buffer, $\mathrm{pH} 7.5$, containing $9 \mathrm{M}$ urea, 2\% (w:v) CHAPS, 2\% (v:v) 2- $\beta$ mercaptoethanol, 8 mM PMSF, $0.8 \%$ (v:v) pharmalytes pH 3-10 and protease inhibitor $\left(16 \mu \mathrm{g} \cdot \mathrm{mL}^{-1}\right.$ aprotinin). The homogenates were stored on ice and sonicated for $30 \mathrm{~s}$ twice (Ultrasonic processor, Fischer-Bioblock, Aubagne, France). Cellular debris was removed by centrifugation at $9000 \times \mathrm{g}$ for $15 \mathrm{~min}$ at $4{ }^{\circ} \mathrm{C}$ and the supernatants stored at $-80{ }^{\circ} \mathrm{C}$ until further analysis. Protein concentrations were determined according to the method of Bradford [32] with bovine serum albumin as a standard.

\subsection{Gel Analysis}

For preparative gels, the homogenates were adjusted to $750 \mu \mathrm{g}$ of total protein with rehydratation buffer containing $9 \mathrm{M}$ urea, 2\% (w:v) CHAPS, $65 \mathrm{mM}$ dithioerythreitol, immobilised $\mathrm{pH}$ gradient (IPG)-buffer and loaded on $18 \mathrm{~cm}$ non-linear wide-range Immobiline Drystrips (pH 3-10, NL/18 cm; GE Healthcare), for overnight passive rehydration. Isoelectric focussing was carried out at $20{ }^{\circ} \mathrm{C}$ using a horizontal Multiphor electrophoresis apparatus (Amersham Pharmacia Biotech) according to the manufacturer's recommendations. Subsequently, IPG strips were incubated in $15 \mathrm{mM}$ dithioerythreitol in equilibration buffer (50 mM Tris buffer, $\mathrm{pH} 6.8$, containing $6 \mathrm{M}$ urea, 4\% SDS, 25\% glycerol) for $12 \mathrm{~min}$ followed by $120 \mathrm{mM}$ iodoacetamide and bromophenol blue in equilibration buffer for $5 \mathrm{~min}$. Second dimension was carried out with $12 \%$ SDS-PAGE gels $(20 \mathrm{~cm} \times 20 \mathrm{~cm} \times 1.5 \mathrm{~cm})$ at $10{ }^{\circ} \mathrm{C}$, using a Protean Plus Dodeca cell (BioRad, Marnes-la-Coquette, France) at $600 \mathrm{~mA}$ for $15 \mathrm{~min}$, followed by $1 \mathrm{~A}$ for $15 \mathrm{~min}$ and $200 \mathrm{~V}$ for $6 \mathrm{~h}$, until the dye front reached the bottom of the gel. The protein spots were visualized by colloidal blue staining and scanned to TIFF images using an Image Scanner (Amersham Pharmacia Biotech). Image analyses were performed using Image Master 2-DE analysis software (Amersham Pharmacia Biotech). In total, five series of 12 gels each were processed and aligned using landmark protein spots. Relative abundance of individual spots was determined against the total spot volume, i.e., the sum of all spots detected on the gel, and the standard deviation in relative abundance was calculated over all gels of the five series. To determine the relative dispersion within spot intensities, 
the coefficient of quartile variation (cqv) was applied as a non-parametric measure of variation: $\mathrm{cqv}=[(\mathrm{Q} 3-\mathrm{Q} 1) /(\mathrm{Q} 3+\mathrm{Q} 1)] \times 100$, where $\mathrm{Q} 1$ and $\mathrm{Q} 3$ are first and third population quartiles and Q3-Q1 is the interquartile range [33].

\subsection{Mass Spectrometry and Protein Identification}

In total, 313 different spots were selected and excised manually. Spots were required to appear repeatedly in $95 \%$ of the gels (within a series of a single run and amongst the different runs), to be well defined and separated as to be picked as individual spots and to provide sufficient material for subsequent protein identification. Duplicate identifications of identical spot positions deriving from different gels were carried out for the majority of spots. Proteins spots were digested by trypsin as follows: spots were washed 3 times for $15 \mathrm{~min}$ in water, twice in destain solution containing $100 \mathrm{mM}$ ammonium bicarbonate and 50\% (v:v) ACN and once in ACN. Proteins were then dried in a speed-vac concentrator (Thermo Fisher Scientific) for $5 \mathrm{~min}$, followed by in-gel overnight digestion in $30 \mu \mathrm{L}$ of a digestion buffer containing $50 \mathrm{mM}$ ammonium bicarbonate and $6 \mathrm{ng} / \mu \mathrm{L}$ sequencing grade modified porcine trypsin. The digestion mixture was extracted with 50\% (v:v) ACN and 5\% (v:v) formic acid and then dried in a speed-vac. Peptide extracts were then resuspended in $12 \mu \mathrm{L}$ of $3 \%$ (v:v) ACN/0.1\% (v:v) formic acid and then analysed with a nano-LC1200 system coupled to a 6340 Ion Trap mass spectrometer equipped with a nanospray source and an HPLC-chip cube interface (Agilent Technologies, Les Ulis, France) as described previously [34]. The five most intensive peaks were subjected to MS/MS after two spectra with a dynamic exclusion time of one minute. The peptide fingerprints were analysed using MASCOT software with the following specifications: enzyme specificity, trypsin; one missed cleavage permitted; carbamidomethylation as fixed modification, methionine oxidation as variable modification; peptide charge, $2+$ and 3+; mass accuracy of 1.6 Da for the parent ions (MS) and 0.6 Da for the fragment ions (MS/MS); ESI-TRAP as instrument; SwissProt and NCBInr as databases; "other metazoan" as taxonomy (SwissProt: 540261 sequences; 191876607 residues and NCBInr: 26.236.801 sequences; 9.088.244.489 residues, respectively). To improve identification, a second search was conducted with the same specifications against EMBL invertebrate EST database (95.448.618 sequences; 18.505.270.330 residues). The amino-acid sequences obtained were used to carry out a MS BLAST-PROT search in NCBI standard Protein Blast to identify proteins by sequence similarity against the available sequence databases. Identified proteins were further confirmed by the number of peptide matches, the degree of protein coverage and the accordance of actual and expected molecular mass $(\mathrm{Mr})$ and isoelectric point (pI). Protein function was analysed with the KEGG Pathway database (http://www.genome.jp/kegg/ pathway.html).

\section{Results and Discussion}

The Mytilus gill proteome was assessed using the same methodology as previously described [4,11], which allowed for cross-validation of identified proteins. However, protein extraction has been standardised and improved so as to obtain highly reproducible gels. Figure 1 shows a representative 2-DE gel from $M$. edulis gills in the broad $\mathrm{pH}$ range of 3-10 with around 700 spots visualized [11]. The ensemble of spots is distributed throughout the gel with well-defined spots. The global pattern is in general agreement with the profiles represented in the literature for the genus Mytilus since the first study of 
Shepard et al. [35]. Numerous other studies have analysed the mussel proteome thereafter, mostly in an ecophysiological $[14,21,25,36]$ or ecotoxicological context [11,13,37-42]. The total number of proteins identified has been increasing continuously across these studies with percentage of identification now mostly exceeding $50 \%$ of spots obtained with gel-based proteomics (Figure 2). For this study, more than 300 different spots were submitted to identification of which 268 spots could be identified. However, about one quarter of the identifications resulted in ambiguous identifications relying on one single peptide only with multiple matches to different proteins. Protein identifications by a single peptide have been retained only in some exceptional cases, where one distinct protein emerged by a clearly higher Mascot score, thus permitting a distinction from the other identifications. The identification for these spots (no. 16, 31, 176 and 184) must be considered only as tentative (Table 1). Eventually, the identification of 203 different proteoforms was considered reliable (Table 1). These comprised 150 different subunits or isoforms, respectively, of a total of 122 different proteins. To the best of our knowledge, this study represents the most comprehensive proteome coverage for the genus Mytilus. The percentage of identification of $65 \%$ of the proteins is in line with the general development of protein identification for Mytilus species (Figure 2), as sequence information on molluscs in general has been improving continuously and expressed sequence tags (ESTs) of Mytilidae now amount to more than 70,000 sequences. Most of the identifications were thus either from mollusc species (59\%), from bivalves (54\%) or directly from Mytilidae (29\%). The remaining protein spots were either unreliable identifications $(21 \%)$ or proteins for which no match at all could be obtained $(14 \%)$. The fact that more than one third of the selected protein spots could not be identified reflects that genomic information for this non-model organism, which has not yet been fully sequenced, is still lacking.

In terms of abundance the 203 identified proteoforms accounted for $40 \%$ of the total protein on the gels, with of actin and tubulin representing $>4 \%$ and $>4.5 \%$, respectively; cytoskeleton proteins as a whole amounted to ca. $13 \%$ (Table 1). The majority of proteins identified were below $1 \%$ of the total protein, except for tubulin $\alpha-1$ chain (spot no. 49), cytoplasmic $\beta$-actin (spot no. 89) and tubulin $\beta$ chain (spot no. 61), the latter, with $>3 \%$, being the most abundant protein (Table 1).

Nearly $70 \%$ of the proteins represented a reasonable cqv below $20 \%$, but only about $10 \%$ (21 proteins) were highly reproducible with a cqv below $10 \%$ (Table 2). On the other hand, almost one third of the proteins (i.e., 62) showed a cqv beyond $20 \%$, indicating that these proteins are highly variable in their abundance, which limits their value for quantitative studies.

Several proteoforms identified with a relatively high confidence exhibited nonetheless important deviations from the expected Mr and pI. Considerably lower Mr than predicted suggest the presence of truncated proteoforms, which might be the result of protein degradation, as for instance Grp94, which is found predominantly in spot no. $4(\mathrm{Mr} 95.115 \mathrm{Da})$ but appears also in spot no. $186(\mathrm{Mr} 16.505 \mathrm{Da})$. It is, however, difficult to interpret such protein degradation as either being due to possible degradation during extraction or to cellular processes prior to protein extraction. The spots no. 150 and 151, identified as actin, give a pertinent example for this problem of interpretation. The corresponding spectra resulted in an unambiguous identification, matching exclusively with actin, although the spots revealed much lower Mr than the major actin spot no. 89. The fact that the tryptic peptides covered the entire span of the protein, suggests that these spots may not represent a degraded form of actin. Alternatively, they may either represent fragments of actin or proteins that share common sequences, i.e., actin-like proteins. 


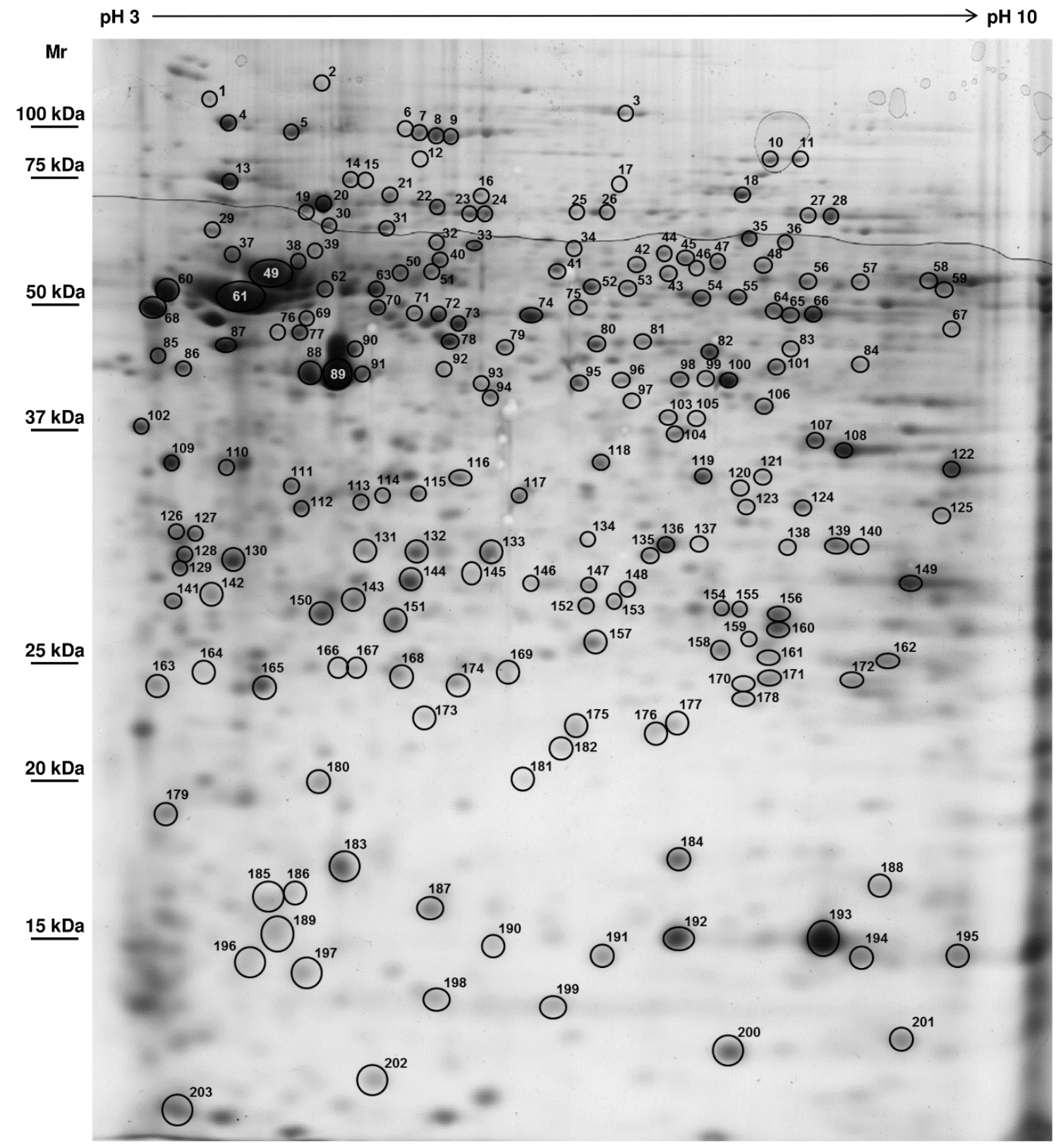

Figure 1. Representative Mytilus edulis gill proteome $(750 \mu \mathrm{g}$ total protein, non-linear pH 3-10, 12\% SDS-PAGE, colloidal blue stain; [11]. Spot numbers correspond to identified proteoforms listed in Table 1. The isoelectric point is indicated on the horizontal axis and the molecular mass $(\mathrm{Mr}$ in $\mathrm{kDa})$ on the vertical axis.

Shifting of proteins relative to their expected $\mathrm{Mr}$ and $\mathrm{pI}$ may also be due to amino acid sequence differences and/or post-translational modifications (PTMs) that may alter protein migration in both, horizontal and vertical directions. In fact, a considerable number of spots resulted in identical protein identifications (see also following sections), although they were recovered from more or less different positions on the gel. It is conceivable that this dispersion of spots relates to a variable degree and kind of PTMs for the respective proteins. In the case of one of the most frequently encountered PTMs, i.e., phosphorylation, a monoisotopic mass difference of $+79.966 \mathrm{Da}$ is added, which does not affect $\mathrm{Mr}$ significantly, but will reduce the $\mathrm{pI}$. Thus, phosphorylated proteins may appear as a characteristic line of horizontal spots depending on their degree of phosphorylation (Figure 1). This may be the case for 
spots no. 6, 7, 8, 9: major vault protein, spots no. 10 and 11: aconitase, for spots no. 23 and 24: hsp70 and for spots no. 27 and 28: phosphoenolpyruvate kinase, all of which are known to be phosphorylated [43-46]. These findings emphasise the potential of studying PTMs in differential-display 2-DE proteomics. Even the usual "déjà vu" proteins [47], such as actin, may contain important information concerning the PTMs. Environmental stress conditions are likely to induce different PTMs to these well-known proteins, amongst them notably the above mentioned phosphorylations $[48,49]$. Accordingly, ubiquitination and carbonylation/glutathionylation have been used in targeted redox proteomics [28,50-53]. Alternative to the quest for new marker proteins, which are not likely to be found amongst the prevalent canonical proteins that are typically revealed by conventional gel-based proteomics, PTMs could be highly informative in the biomonitoring of environmental changes and therefore deserve to be given more attention [54,55]. Furthermore, as long as limited genomic information still hampers sequence-homology searches, the analysis of PTMs of highly conserved proteins, which can be identified unambiguously, is a promising option to evaluate an organism's health or physiological state. This would constitute a particular strength of proteomics, since the focus would be not on the induction of genes or the quantity of a given protein, but on protein function and its regulation as well as modification.

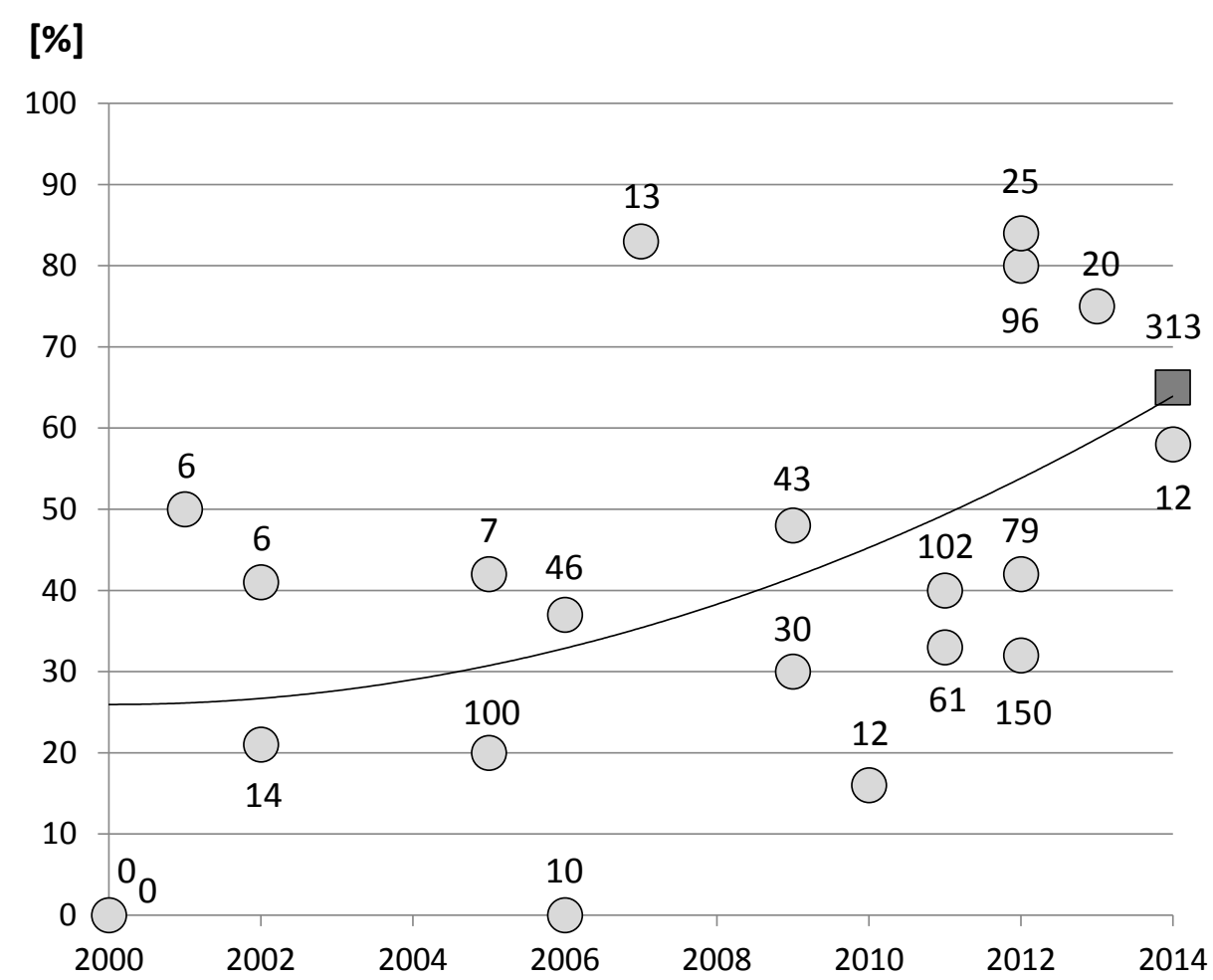

Figure 2. Number of spots identified by proteomics studies in the years 2000-2014 using the Mytilus complex (i.e., Mytilus edulis, Mytilus galloprovincialis, Mytilus trossulus and hybrids thereof) $[4,11,21,35,37,39,41,42,51,56-65]$ : the numerical data represent the number of proteins submitted to identification for each study. The 2 nd order polynomial function illustrates the trend to an increased percentage of spots identified for Mytilus species. The dark grey square depicts the percentage of identification of the present study (65\%) for which a total of 313 different spots were submitted for identification by nanoLC-MS/MS. 
Table 1. Protein spots identified by tandem mass spectrometry in Mytilus edulis gills. Proteins were designated according to NCBI entries and classified with KEGG Pathway database. Spot number code for identification corresponds to spot numbers as depicted in Figure 1. Mr: molecular mass; pI: isoelectric point; obs.: observed; calc.: calculated; seq.: number of matched peptide sequences; cov.: sequence coverage in \%; rel. Ab.: relative abundance in \%o and SD thereof. Tentative identifications by one peptide only (see text) are represented as grey lines.

\begin{tabular}{|c|c|c|c|c|c|c|c|c|c|c|c|c|}
\hline \begin{tabular}{l|l}
$\mathbf{N}^{\circ}$ \\
\end{tabular} & Name & \multicolumn{2}{|c|}{ Mr obs.pI obs. } & species & number I & \multicolumn{2}{|c|}{ Mr calc.pI calc. } & \multicolumn{4}{|c|}{ seq. cov.rel. Ab. } & \multirow[t]{2}{*}{ SD } \\
\hline \multicolumn{12}{|c|}{ Metabolism; Carbohydrate metabolism; Amino sugar and nucleotide sugar metabolism } & \\
\hline 79 & fumarylacetoacetate hydrolase, similar & 46744 & 5.76 & Trichoplax adhaerens & gi|195998011 & 46138 & 5.89 & 85 & 2 & 5 & 0.86 & 0.08 \\
\hline 125 & GDP-L-fucose synthetase & 32148 & 8.21 & Crassostrea gigas & gi| 405958300 & 35147 & 6.41 & 76 & 3 & 8 & 1.77 & 0.21 \\
\hline 172 & glucosamine phosphate isomerase & 24602 & 7.51 & Idiogaryops pumilis & gi|262304349 & 19748 & 5.39 & 66 & 2 & 13 & 1.91 & 0.18 \\
\hline 103 & UDP-glucose 4-epimerase & 38721 & 6.31 & Crassostrea gigas & gi|405968861 & 37674 & 6.72 & 113 & 4 & 14 & 0.92 & 0.13 \\
\hline 34 & UDP-N-acetylglucosamine pyrophosphorylase, provisional & 60863 & 5.97 & Capitella teleta & gi|443696999 & 57560 & 6.14 & 99 & 2 & 5 & 0.47 & 0.05 \\
\hline 42 & UDP-N-acetylglucosamine pyrophosphorylase, provisional & 57755 & 6.18 & Capitella teleta & gi|443696999 & 57560 & 6.14 & 98 & 2 & 5 & 0.67 & 0.12 \\
\hline \multicolumn{13}{|c|}{ Metabolism; Carbohydrate metabolism; Glycolysis / Gluconeogenesis } \\
\hline 74 & enolase & 49971 & 5.84 & Tomocerus sp. jcrjws1 & gi|8101744 & 41585 & 5.37 & 190 & 4 & 16 & 4.02 & 0.29 \\
\hline 93 & fructose-bisphosphate aldolase & 41755 & 5.69 & Crassostrea gigas & gi|405964948 & 43741 & 5.88 & 131 & 2 & 8 & 0.87 & 0.06 \\
\hline 104 & fructose-bisphosphate aldolase & 37405 & 6.34 & Mytilus edulis & gi|46909221 & 21776 & 5.86 & 186 & 4 & 23 & 0.97 & 0.07 \\
\hline 122 & glyceraldehyde-3-phosphate dehydrogenase & 35098 & 8.37 & Crassostrea gigas & gi|405957058 & 36402 & 6.95 & 195 & 4 & 9 & 4.78 & 0.37 \\
\hline 156 & glyceraldehyde-3-phosphate dehydrogenase A (EC 1.2.1.12) & 27219 & 6.91 & Urticina eques & gi|124264159 & 32082 & 6.51 & 70 & 2 & 8 & 3.96 & 0.18 \\
\hline 37 & NADPH-dependent aldehyde reductase, putative & 60059 & 4.94 & Mytilus galloprovincialis & FL493052 & 29121 & 5.54 & 135 & 3 & 16 & 2.71 & 0.19 \\
\hline 27 & phosphoenolpyruvate carboxykinase & 67990 & 7.12 & Loa loa & gi|312080904 & 72497 & 6.52 & 76 & 4 & 4 & 1.03 & 0.14 \\
\hline 28 & phosphoenolpyruvate carboxykinase & 67990 & 7.22 & Loa loa & gi|312080904 & 72497 & 6.52 & 76 & 4 & 4 & 1.21 & 0.14 \\
\hline 101 & phosphoglycerate kinase & 43890 & 6.85 & Caenorhabditis brenneri & gi|341896690 & 44295 & 6.28 & 291 & 6 & 18 & 2.30 & 0.31 \\
\hline 84 & phosphoglycerate kinase & 43890 & 7.41 & Crassostrea gigas & gi|405963233 & 44217 & 7.59 & 85 & 4 & 13 & 1.18 & 0.11 \\
\hline 163 & phosphoglycerate mutase 1 & 25755 & 4.55 & Pelodictyon phaeoclathratiforme & Q3VP85_9CHLB & 28466 & 5.20 & 72 & 2 & 8 & 2.90 & 0.38 \\
\hline 159 & triosephosphate isomerase & 25844 & 6.75 & Mytilus edulis & gi|46909461 & 16417 & 4.93 & 233 & 5 & 33 & 1.88 & 0.14 \\
\hline 157 & triosephosphate isomerase, partial & 25666 & 6.04 & Mytilus edulis & gi|46909461 & 16417 & 4.93 & 330 & 6 & 31 & 1.74 & 0.07 \\
\hline
\end{tabular}


Table 1. Cont

\begin{tabular}{|c|c|c|c|c|c|c|c|c|c|c|c|c|}
\hline $\mathbf{N}^{\circ}$ & Name & \multicolumn{2}{|c|}{ Mr obs.pI obs. } & species & access number & \multicolumn{2}{|c|}{ Mr calc.pI calc. } & \multicolumn{4}{|c|}{\begin{tabular}{|l|l|l|} 
e seq. & cov. & rel. Ab. \\
\end{tabular}} & SD \\
\hline \multicolumn{13}{|c|}{ Metabolism; Carbohydrate metabolism; Citrate cycle (TCA cycle) } \\
\hline 10 & aconitase 2 , mitochondrial isoform 2 , similar & 83797 & 6.8 & Strongylocentrotus purpuratus & gi| $\mid 115735566$ & 65256 & 4.96 & 105 & 3 & 6 & 0.70 & 0.07 \\
\hline 11 & aconitase 2, mitochondrial isoform 2, similar & 83797 & 6.97 & Strongylocentrotus purpuratus & gi|115936456 & 84808 & 5.49 & 219 & 4 & 7 & 0.64 & 0.09 \\
\hline 82 & citrate synthase, mitochondrial, predicted & 45275 & 6.49 & Strongylocentrotus purpuratus & gi|390339579 & 51662 & 6.09 & 101 & 3 & 7 & 1.67 & 0.17 \\
\hline 54 & dihydrolipoamide dehydrogenase & 52991 & 6.55 & Trichoplax adhaerens & gi|196005079 & 48079 & 6.74 & 105 & 2 & 5 & 1.35 & 0.14 \\
\hline 98 & isocitrate dehydrogenase & 42584 & 6.36 & Crassostrea gigas & gi|48476117 & 51365 & 8.52 & 245 & 5 & 14 & 1.17 & 0.11 \\
\hline 99 & isocitrate dehydrogenase & 42584 & 6.47 & Crassostrea gigas & gi|48476117 & 51365 & 8.52 & 216 & 7 & 17 & 0.52 & 0.04 \\
\hline 100 & isocitrate dehydrogenase & 42584 & 6.60 & Crassostrea gigas & gi|48476117 & 51365 & 8.52 & 445 & 9 & 20 & 2.94 & 0.21 \\
\hline 161 & isocitrate dehydrogenase & 24686 & 6.88 & Mytilus trossulus & gi|385268539 & 50918 & 6.77 & 63 & 2 & 5 & 1.70 & 0.21 \\
\hline 171 & isocitrate dehydrogenase & 25226 & 6.88 & Mytilus trossulus & gi|385268539 & 50918 & 6.77 & 63 & 2 & 5 & 2.21 & 0.18 \\
\hline 136 & malate dehydrogenase, cytosolic & 30138 & 6.33 & Mytilus galloprovincialis & gi|73656337 & 36628 & 6.02 & 222 & 6 & 24 & 2.37 & 0.23 \\
\hline 119 & malate dehydrogenase, mitochondrial & 34527 & 6.48 & Candida albicans & gi|68466091 & 34821 & 5.73 & 68 & 3 & 9 & 1.95 & 0.08 \\
\hline 121 & malate dehydrogenase, mitochondrial & 34527 & 6.80 & Crassostrea gigas & gi| 405963427 & 30046 & 8.20 & 64 & 2 & 7 & 0.62 & 0.06 \\
\hline 118 & malate deshydrogenase, cytosolic & 35390 & 6.07 & Mytilus galloprovincialis & gi|73656337 & 36628 & 6.02 & 869 & 16 & 49 & 2.44 & 0.18 \\
\hline 113 & pyruvate dehydrogenase E1 component subunit beta, mitochondrial & 32652 & 5.39 & Ascaris suum & gi|129066 & 39681 & 5.84 & 108 & 3 & 8 & 1.62 & 0.16 \\
\hline \multicolumn{13}{|c|}{ Metabolism; Carbohydrate metabolism; Pentose phosphate pathway } \\
\hline 36 & transketolase & 62469 & 6.90 & Strongylocentrotus purpuratus & gi|336455050 & 67029 & 5.96 & 118 & 3 & 5 & 0.61 & 0.08 \\
\hline \multicolumn{13}{|c|}{ Metabolism; Energy metabolism; Transferring phosphorus-containing groups } \\
\hline 107 & arginine kinase & 36605 & 7.29 & Macrobiotus occidentalis & gi|308199061 & 40207 & 6.91 & 89 & 2 & 8 & 2.44 & 0.17 \\
\hline 108 & arginine kinase & 36605 & 7.68 & Conus novaehollandiae & gi|301341836 & 39664 & 6.34 & 123 & 2 & 3 & 3.95 & 0.43 \\
\hline \multicolumn{13}{|c|}{ Metabolism; Energy metabolism; Oxidative phosphorylation } \\
\hline 64 & ATP synthase alpha subunit mitochondrial & 51140 & 6.84 & Crassostrea gigas & gi|405974703 & 60000 & 8.48 & 505 & 11 & 18 & 1.56 & 0.12 \\
\hline 65 & ATP synthase alpha subunit mitochondrial & 50843 & 6.92 & Litopenaeus vannamei & gi|288816877 & 59416 & 8.97 & 284 & 8 & 12 & 2.50 & 0.35 \\
\hline 66 & ATP synthase alpha subunit mitochondrial & 50549 & 7.11 & Pinctada fucata & gi|116008297 & 59814 & 8.92 & 764 & 14 & 23 & 3.29 & 0.31 \\
\hline 87 & ATP synthase beta subunit & 46535 & 4.90 & Mytilus edulis & gi|46909261 & 46288 & 4.97 & 885 & 16 & 53 & 1.94 & 0.14 \\
\hline 152 & ETF beta-like & 27504 & 6.02 & Nasonia vitripennis & gi|156543370 & 27498 & 7.66 & 236 & 6 & 19 & 1.11 & 0.07 \\
\hline 67 & NADH dehydrogenase (ubiquinone) flavoprotein 1, mitochondrial & 48850 & 8.37 & Crassostrea gigas & gi|405967555 & 51955 & 8.39 & 171 & 5 & 11 & 1.01 & 0.17 \\
\hline
\end{tabular}


Table 1. Cont.

\begin{tabular}{|c|c|c|c|c|c|c|c|c|c|c|c|c|}
\hline \multirow{2}{*}{\begin{tabular}{l|}
$\mathbf{N}^{\circ}$ \\
164 \\
\end{tabular}} & \multirow{2}{*}{\begin{tabular}{|c|} 
Name \\
NADH dehydrogenase [ubiquinone] iron-sulfur protein 8, mitochondrial-like
\end{tabular}} & \multicolumn{2}{|c|}{ Mr obs.pI obs. } & \multirow{2}{*}{$\begin{array}{c}\text { species } \\
\text { Metaseiulus occidentalis }\end{array}$} & \multirow{2}{*}{\begin{tabular}{|c|} 
access number \\
gi|391342248 \\
\end{tabular}} & \multicolumn{2}{|c|}{ Mr calc.pI calc. } & \multicolumn{4}{|c|}{ score seq.cov.rel. Ab. } & \multirow{2}{*}{\begin{tabular}{|l|l|} 
SD \\
0.05 \\
\end{tabular}} \\
\hline & & 24770 & 4.83 & & & 24721 & 5.42 & 62 & 2 & 10 & 0.86 & \\
\hline 14 & NADH dehydrogenase subunit, hypothetical protein DAPPUDRAFT_192333 & 75534 & 5.38 & Daphnia pulex & gi|321476647 & 80103 & 6.00 & 162 & 3 & 4 & 0.55 & 0.05 \\
\hline 15 & NADH-ubiquinone oxidoreductase $75 \mathrm{kDa}$ subunit, mitochondrial & 75534 & 5.33 & Crassostrea gigas & gi|405977043 & 81477 & 5.84 & 180 & 5 & 6 & 0.28 & 0.03 \\
\hline 188 & nucleoside diphosphate kinase & 17020 & 7.99 & Ostrea edulis & gi|388571212 & 18860 & 6.82 & 65 & 2 & 12 & 4.98 & 0.89 \\
\hline 22 & succinate dehydrogenase (ubiquinone) flavoprotein subunit & 67990 & 5.59 & Clonorchis sinensis & gi|358254399 & 72276 & 7.09 & 185 & 3 & 5 & 0.97 & 0.10 \\
\hline 83 & succinate-semialdehyde dehydrogenase, mitochondrial & 45998 & 6.92 & Mytilus californianus & GE753097 & 29091 & 8.82 & 84 & 2 & 8 & 1.41 & 0.48 \\
\hline 167 & ubiquinol-cytochrome c reductase, Rieske iron-sulfur polypeptide 1 & 24770 & 5.37 & Mytilus galloprovincialis & FL489022 & 22838 & 9.08 & 283 & 5 & 30 & 1.53 & 0.15 \\
\hline 149 & voltage-dependent anion selective channel protein 2, probable & 28679 & 8.24 & Mytilus californianus & GE752193 & 23286 & 5.38 & 164 & 3 & 17 & 6.18 & 0.61 \\
\hline \multicolumn{13}{|c|}{ Metabolism; Lipid metabolism } \\
\hline 154 & enoyl-CoA hydratase, mitochondrial-like & 27314 & 6.57 & Amphimedon queenslandica & gi|340375594 & 31912 & 5.82 & 74 & 2 & 10 & 1.27 & 0.07 \\
\hline 155 & enoyl-CoA hydratase, mitochondrial-like & 27314 & 6.68 & Amphimedon queenslandica & gi|340375594 & 31912 & 5.82 & 100 & 2 & 10 & 1.54 & 0.08 \\
\hline 165 & fatty acid-binding protein, provisional & 24021 & 5.06 & Mytilus galloprovincialis & FL498602 & 21271 & 8.51 & 171 & 4 & 33 & 3.69 & 0.25 \\
\hline 111 & inorganic pyrophosphatase-like & 33434 & 5.17 & Mytilus californianus & ES407080 & 41244 & 8.71 & 152 & 3 & 7 & 1.63 & 0.11 \\
\hline 97 & long-chain specific acyl-CoA dehydrogenase, mitochondrial precursor & 40566 & 6.17 & Homo sapiens & gi|4501857 & 48024 & 7.68 & 90 & 2 & 6 & 0.70 & 0.08 \\
\hline \multicolumn{13}{|c|}{ Metabolism; Amino acid metabolism } \\
\hline 3 & glycine dehydrogenase & 100445 & 6.12 & Mytilus galloprovincialis & FL490887 & 29626 & 8.23 & 84 & 2 & 10 & 0.47 & 0.05 \\
\hline 30 & delta-1-pyrroline-5-carboxylate dehydrogenase, mitochondrial & 63776 & 5.27 & Crassostrea gigas & gi|405978465 & 64148 & 8.35 & 74 & 2 & 3 & 0.54 & 0.03 \\
\hline 57 & amine oxidase, predicted & 54915 & 7.44 & Nematostella vectensis & gi| 156382450 & 58581 & 6.54 & 54 & 2 & 4 & 0.76 & 0.09 \\
\hline 60 & procollagen-proline dioxygenase beta subunit & 55950 & 4.62 & Mytilus galloprovincialis & gi|390979785 & 55402 & 4.53 & 449 & 13 & 25 & 7.01 & 0.42 \\
\hline 95 & glutamine synthetase & 42166 & 5.98 & Tegillarca granosa & gi|306489668 & 41952 & 5.63 & 203 & 4 & 12 & 1.43 & 0.08 \\
\hline 106 & cystathionine gamma-lyase & 39809 & 6.80 & Capitella teleta & gi|443685366 & 43775 & 6.14 & 78 & 2 & 4 & 1.23 & 0.08 \\
\hline 123 & 3-hydroxyanthranilate 3,4-dioxygenase & 32399 & 6.70 & Suberites domuncula & gi|18076468 & 32433 & 5.57 & 70 & 2 & 5 & 0.77 & 0.07 \\
\hline \multicolumn{13}{|c|}{ Metabolism; Metabolism of other amino-acids } \\
\hline 135 & S-formylglutathione hydrolase & 29472 & 6.25 & Acromyrmex echinatior & gi|332027837 & 18955 & 6.58 & 138 & 2 & 9 & 1.03 & 0.08 \\
\hline \multicolumn{13}{|c|}{ Metabolism; Glycan biosynthesis and metabolism } \\
\hline 112 & short chain collagen $\mathrm{C} 4$, putative & 32148 & 5.20 & Mytilus galloprovincialis & EH 663252 & 32880 & 8.72 & 373 & 7 & 34 & 1.15 & 0.12 \\
\hline
\end{tabular}


Table 1. Cont

\begin{tabular}{|c|c|c|c|c|c|c|c|c|c|c|c|c|}
\hline $\mathbf{N}^{\circ}$ & Name & \multicolumn{2}{|c|}{ Mr obs.pI obs. } & species & number & \multicolumn{2}{|c|}{ Mr calc.pI calc. } & \multicolumn{4}{|c|}{\begin{tabular}{l|l|l|l|} 
re & seq. & cov. & rel. Ab. \\
\end{tabular}} & SD \\
\hline \multicolumn{13}{|c|}{ Metabolism; Metabolism of cofactors and vitamins; Ubiquinone and other terpenoid-quinone biosynthesis } \\
\hline 47 & ubiquinone biosynthesis monooxygenase COQ6 & 58506 & 6.53 & Harpegnathos saltator & gi|307192550 & 52851 & 8.79 & 66 & 2 & 2 & 0.68 & 0.07 \\
\hline 193 & ubiquinone biosynthesis monooxygenase COQ6 & 15255 & 7.27 & Harpegnathos saltator & gi|307192550 & 52851 & 8.79 & 59 & 2 & 2 & 4.38 & 1.35 \\
\hline \multicolumn{13}{|c|}{ Genetic Information Processing; Transcription } \\
\hline 114 & transcriptional activator protein pur-alpha & 33170 & 5.45 & Crassostrea gigas & gi|405974727 & 27930 & 6.78 & 265 & 6 & 23 & 1.13 & 0.06 \\
\hline 115 & pur-alpha, putative & 33170 & 5.55 & Ixodes scapularis & gi|242046488 & 26667 & 9.41 & 111 & 2 & 11 & 1.56 & 0.11 \\
\hline \multicolumn{13}{|c|}{ Genetic Information Processing; Translation } \\
\hline 86 & 40S ribosomal prot SA (p 40) $(34 / 67 \mathrm{kDa}$ laminin receptor) & 43011 & 4.69 & Pinctada fucata & gi|229891605 & 33727 & 5.24 & 185 & 4 & 12 & 1.73 & 0.13 \\
\hline 183 & eIF5A like & 17469 & 5.35 & Mytilus galloprovincialis & AJ516752 & 19880 & 5.23 & 226 & 5 & 38 & 6.48 & 0.79 \\
\hline 51 & elongation factor 1 alpha & 56303 & 5.51 & Mytilus edulis & gi|299474235 & 50827 & 9.12 & 174 & 5 & 14 & 0.56 & 0.07 \\
\hline 71 & elongation factor 1 alpha 1 & 49971 & 5.53 & Saccoglossus kowalevskii & gi|296317283 & 50711 & 9.34 & 134 & 3 & 7 & 1.75 & 0.24 \\
\hline 160 & Hadh2-prov protein isoform 1, similar & 26477 & 6.91 & Strongylocentrotus purpuratus & gi|72006882 & 27479 & 6.32 & 87 & 2 & 10 & 4.13 & 0.15 \\
\hline 25 & phenylalanyl-tRNA synthetase beta chain, probable & 67990 & 5.92 & Mytilus galloprovincialis & FL494288 & 25820 & 5.63 & 138 & 4 & 17 & 0.84 & 0.07 \\
\hline 26 & phenylalanyl-tRNA synthetase beta chain, probable & 67990 & 6.15 & Mytilus galloprovincialis & FL494288 & 25820 & 5.63 & 99 & 2 & 9 & 0.94 & 0.12 \\
\hline 46 & PRP19/PSO4 pre-mRNA processing factor 19 homolog, predicted & 57755 & 6.43 & Saccoglossus kowalevskii & gi|291228334 & 56436 & 6.60 & 78 & 2 & 6 & 0.49 & 0.04 \\
\hline 199 & ribosomal protein rps 12 & 13157 & 5.94 & Lineus viridis & gi|166952363 & 13852 & 8.13 & 119 & 5 & 29 & 3.39 & 0.60 \\
\hline 185 & ribosomal protein rps13 & 16142 & 5.11 & Arenicola marina & gi|158187708 & 17169 & 10.59 & 74 & 2 & 17 & 1.74 & 0.16 \\
\hline 198 & ribosomal protein $\mathrm{S} 12$ & 13258 & 5.62 & Periplaneta americana & gi|21217441 & 15585 & 5.95 & 106 & 3 & 15 & 4.24 & 0.37 \\
\hline 137 & ribosomal protein S2 & 30138 & 6.48 & Chlamys farreri & gi|22203717 & 27078 & 10.49 & 147 & 5 & 26 & 0.65 & 0.07 \\
\hline \multicolumn{13}{|c|}{ Genetic Information Processing; Folding, sorting and degradation; Folding and sorting } \\
\hline 13 & $78 \mathrm{kDa}$ glucose regulated protein & 75534 & 4.87 & Crassostrea gigas & gi| 46359618 & 73088 & 5.02 & 567 & 11 & 16 & 3.93 & 0.36 \\
\hline 68 & calreticulin, predicted & 50750 & 4.76 & Mytilus galloprovincialis & FL593839 & 27230 & 5.24 & 564 & 12 & 44 & 8.28 & 0.36 \\
\hline 85 & calumenin precursor, putative & 44572 & 4.76 & Pediculus humanus corporis & gi|242005220 & 37885 & 4.61 & 65 & 2 & 3 & 3.60 & 0.20 \\
\hline 38 & chaperonin & 56660 & 5.18 & Paracentrotus lividus & gi|5912574 & 62195 & 5.12 & 203 & 4 & 11 & 3.67 & 0.47 \\
\hline 146 & endoplasmic reticulum protein ERp29 & 28479 & 5.85 & Crassostrea gigas & gi|405975720 & 28444 & 5.19 & 141 & 3 & 8 & 1.09 & 0.13 \\
\hline 4 & glucose-regulated protein 94 & 95115 & 4.88 & Crassostrea gigas & gi|148717303 & 91795 & 4.83 & 384 & 8 & 10 & 1.60 & 0.18 \\
\hline 186 & glucose-regulated protein 94 (fragment) & 16505 & 5.19 & Crassostrea gigas & gi|148717303 & 91795 & 4.83 & 101 & 2 & 3 & 1.25 & 0.08 \\
\hline
\end{tabular}


Table 1. Cont.

\begin{tabular}{|c|c|c|c|c|c|c|c|c|c|c|c|c|}
\hline $\mathbf{N}^{\circ}$ & Name & Mr obs & pI obs. & species & access number & Mr calc. & pI calc. & score & seq. & cov. & rel. Ab. & SD \\
\hline 20 & heat shock cognate 71 & 68990 & 5.25 & Mytilus galloprovincialis & gi|76780612 & 71508 & 5.29 & 1515 & 28 & 46 & 4.93 & 0.23 \\
\hline 39 & heat shock protein 60 & 60059 & 5.23 & Biomphalaria glabrata & gi|218683627 & 31076 & 5.41 & 400 & 8 & 12 & 1.02 & 0.17 \\
\hline 23 & heat shock protein 70 & 67013 & 5.64 & Mytilus galloprovincialis & gi|62989584 & 68848 & 5.35 & 90 & 3 & 6 & 0.75 & 0.09 \\
\hline 24 & heat shock protein 70 & 67013 & 5.71 & Mytilus galloprovincialis & gi|62989584 & 69848 & 5.35 & 238 & 5 & 8 & 0.82 & 0.12 \\
\hline 12 & heat shock protein 90 & 81772 & 5.54 & Mytilus galloprovincialis & gi|205362524 & 83358 & 4.85 & 179 & 4 & 7 & 0.45 & 0.07 \\
\hline 75 & NFX1-type containing zinc finge, similar & 51140 & 5.99 & Hydra magnipapillata & gi|221116469 & 395486 & 8.08 & 59 & 3 & 0 & 3.20 & 1.15 \\
\hline 143 & prohibitin & 27504 & 5.38 & Trichinella spiralis & gi|339249751 & 60213 & 6.90 & 129 & 4 & 6 & 2.40 & 0.17 \\
\hline 70 & protein disulfide-isomerase, like & 50843 & 5.42 & Mytilus californianus & GE750884 & 30856 & 5.07 & 198 & 4 & 19 & 1.54 & 0.09 \\
\hline 55 & protein disulfide-isomerase, predicted & 52991 & 6.64 & Trichoplax adhaerens & gi|196002337 & 52300 & 8.18 & 76 & 2 & 5 & 1.14 & 0.08 \\
\hline 166 & putative small $22 \mathrm{kd}$ heat shock protein & 24770 & 5.35 & Mytilus californianus & ES737901 & 25707 & 5.94 & 80 & 2 & 11 & 1.39 & 0.11 \\
\hline 168 & small $22 \mathrm{kd}$ heat shock protein, putative & 24518 & 5.49 & Mytilus californianus & ES737901 & 25707 & 5.94 & 80 & 2 & 11 & 1.98 & 0.13 \\
\hline 131 & small heat shock protein 24.1 & 29692 & 5.4 & Mytilus galloprovincialis & gi|347545633 & 28691 & 5.61 & 163 & 3 & 12 & 1.42 & 0.12 \\
\hline 132 & small heat shock protein 24.1 & 29582 & 5.54 & Mytilus galloprovincialis & gi|347545633 & 28691 & 5.61 & 200 & 4 & 15 & 2.34 & 0.27 \\
\hline 133 & small heat shock protein 24.1 & 29582 & 5.73 & Mytilus galloprovincialis & gi|347545633 & 28691 & 5.61 & 534 & 12 & 48 & 2.57 & 0.20 \\
\hline 144 & Small heat shock protein 24.1 & 28479 & 5.52 & Mytilus galloprovincialis & gi|347545633 & 28691 & 5.61 & 75 & 2 & 9 & 3.71 & 0.34 \\
\hline 145 & small heat shock protein 24.1 & 28881 & 5.64 & Mytilus galloprovincialis & gi|347545633 & 28691 & 5.61 & 84 & 2 & 8 & 2.18 & 0.45 \\
\hline 148 & small heat shock protein 24.1 & 28280 & 6.17 & Mytilus galloprovincialis & gi|347545633 & 28691 & 5.61 & 96 & 2 & 8 & 0.93 & 0.07 \\
\hline 19 & stress-70 protein, mitochondrial, predicted mortaline-like & 67499 & 5.21 & Strongylocentrotus purpuratus & gi|72014569 & 76579 & 5.51 & 264 & 6 & 8 & 1.06 & 0.15 \\
\hline 56 & TCP1 subunit epsilon like, hypothetical protein SINV_10604 & 54915 & 7.29 & Solenopsis invicta & gi|322800807 & 59845 & 5.80 & 172 & 4 & 9 & 0.77 & 0.08 \\
\hline 48 & TCP1 subunit zeta & 57755 & 6.77 & Haliotis discus hannai & gi|379318220 & 58706 & 6.53 & 186 & 4 & 12 & 0.66 & 0.06 \\
\hline 45 & TCP1, hypothetical protein & 58506 & 6.37 & Amblyomma maculatum & gi|346470969 & 59522 & 5.96 & 333 & 8 & 16 & 0.84 & 0.13 \\
\hline 33 & TCP1, subunit beta-like & 61272 & 5.69 & Saccoglossus kowalevskii & gi|291227173 & 150827 & 8.07 & 148 & 4 & 3 & 1.05 & 0.07 \\
\hline 44 & TCP1, subunit gamma isoform 1 & 60059 & 6.29 & Strongylocentrotus purpuratus & gi|115711990 & 60965 & 7.85 & 120 & 4 & 7 & 0.58 & 0.06 \\
\hline 43 & TCP1, subunit eta-like isoform 1 & 55950 & 6.29 & Bombus terrestris & gi|340715736 & 60400 & 6.22 & 193 & 3 & 7 & 0.56 & 0.05 \\
\hline 40 & TCP1, subunit theta & 58128 & 5.59 & Crassostrea gigas & gi|405961548 & 83831 & 5.67 & 175 & 4 & 6 & 0.70 & 0.06 \\
\hline 180 & translationally controlled tumour protein & 20172 & 5.28 & Mytilus californianus & gi|359359687 & 19635 & 4.76 & 71 & 2 & 15 & 1.43 & 0.24 \\
\hline 187 & tubulin-specific chaperone a-like & 16150 & 5.65 & Mytilus californianus & ES738008 & 26274 & 6.17 & 147 & 4 & 19 & 2.87 & 0.22 \\
\hline 5 & valosin-containing protein-like & 93484 & 5.14 & Saccoglossus kowalevskii & gi|291242207 & 90395 & 5.18 & 296 & 6 & 10 & 0.87 & 0.10 \\
\hline
\end{tabular}


Table 1. Cont

\begin{tabular}{|c|c|c|c|c|c|c|c|c|c|c|c|c|}
\hline $\mathbf{N}^{\circ}$ & Name & \multicolumn{2}{|c|}{ Mr obs.pI obs. } & species & number & \multicolumn{2}{|c|}{ Mr calc.pI calc. } & \multicolumn{4}{|c|}{ seq. cov.rel. Ab. } & SD \\
\hline \multicolumn{13}{|c|}{ Genetic Information Processing; Folding, sorting and degradation; Proteasome } \\
\hline 76 & $26 \mathrm{~S}$ protease regulatory subunit $6 \mathrm{a}$ RT5 & 48040 & 5.09 & Crassostrea gigas & gi|405957859 & 48206 & 5.08 & 303 & 5 & 14 & 0.86 & 0.17 \\
\hline 77 & $26 \mathrm{~S}$ protease regulatory subunit $6 \mathrm{a}$ RPT5 & 47776 & 5.18 & Aedes aegypti & gi|157129681 & 47953 & 5.20 & 269 & 6 & 17 & 1.71 & 0.17 \\
\hline 96 & 26S proteasome regulatory complex ATPase RPT4 & 42584 & 6.12 & Daphnia pulex & gi|321461635 & 44199 & 6.10 & 291 & 6 & 22 & 1.04 & 0.09 \\
\hline 69 & $26 \mathrm{~S}$ proteasome regulatory subunit $\mathrm{T} 3$ & 49405 & 5.21 & Schistosoma japonicum & gi|226471414 & 46930 & 5.29 & 563 & 13 & 32 & 0.85 & 0.10 \\
\hline 17 & E3 ubiquitin-protein ligase TRIM33 & 75534 & 6.05 & Mytilus galloprovincialis & AJ625521 & 20697 & 7.07 & 174 & 4 & 24 & 0.26 & 0.04 \\
\hline 120 & proteasome 26S subunit, non-ATPase 14-like, predicted & 33836 & 6.69 & Saccoglossus kowalevskii & gi|291239801 & 34852 & 6.07 & 89 & 3 & 9 & 0.82 & 0.09 \\
\hline 142 & proteasome alpha 5 subunit-like & 27889 & 4.88 & Saccoglossus kowalevskii & gi|291243435 & 26525 & 4.74 & 268 & 4 & 22 & 1.24 & 0.07 \\
\hline 169 & proteasome alpha type 2 & 24435 & 5.79 & Haliotis discus discus & gi|126697376 & 26249 & 5.73 & 173 & 3 & 18 & 1.35 & 0.10 \\
\hline 177 & proteasome beta type- 6 subunit & 22320 & 6.33 & Mytilus californianus & ES387982 & 30469 & 7.13 & 421 & 9 & 43 & 1.15 & 0.12 \\
\hline 147 & proteasome subunit alpha type- 4 & 28280 & 6.04 & Crassostrea gigas & gi|405964515 & 21464 & 5.69 & 70 & 2 & 13 & 1.26 & 0.17 \\
\hline 153 & proteasome subunit alpha type- 6 & 27600 & 6.12 & Crassostrea gigas & gi|405975869 & 25429 & 7.57 & 182 & 4 & 18 & 1.13 & 0.10 \\
\hline 176 & ubiquination linked effector, hypothetical protein CRE_31518 & 22248 & 6.26 & Caenorhabditis remanei & gi|308460407 & 37338 & 8.82 & 57 & 1 & 2 & 0.97 & 0.08 \\
\hline \multicolumn{13}{|c|}{ Genetic Information Processing; Replication and repair } \\
\hline 197 & histone $\mathrm{H} 2 \mathrm{~B}$ & 13942 & 5.23 & Mytilus edulis & gi|23304756 & 13781 & 10.69 & 91 & 2 & 19 & 2.35 & 0.22 \\
\hline 202 & histone H4 & 12350 & 5.76 & Diprion pini & gi|1883030 & 11141 & 11.51 & 79 & 3 & 32 & 1.17 & 0.08 \\
\hline 41 & meiosis-specific nuclear structural protein 1-like & 57021 & 5.91 & Saccoglossus kowalevskii & gi|291241736 & 61112 & 5.52 & 107 & 3 & 3 & 0.76 & 0.09 \\
\hline \multicolumn{13}{|c|}{ Environmental Information Processing; Signal transduction } \\
\hline 128 & 14-3-3 epsilon protein & 29364 & 4.71 & Bombyx mori & gi|148298752 & 29767 & 4.66 & 267 & 7 & 24 & 1.55 & 0.14 \\
\hline 130 & 14-3-3 epsilon protein & 29364 & 4.95 & Lepeophtheirus salmonis & gi $\mid 155966250$ & 28466 & 4.67 & 102 & 3 & 8 & 3.44 & 0.27 \\
\hline 129 & 14-3-3 epsilon protein & 28980 & 4.69 & Bombyx mori & gi|148298752 & 29767 & 4.66 & 214 & 7 & 24 & 2.07 & 0.28 \\
\hline 174 & calcyphosin-like protein & 24505 & 5.61 & Mytilus galloprovincialis & FL489968 & 22644 & 7.00 & 141 & 2 & 10 & 1.64 & 0.28 \\
\hline 18 & EF-hand domain-containing protein 1 & 72142 & 6.66 & Crassostrea gigas & gi|405964721 & 74735 & 6.23 & 126 & 4 & 5 & 1.10 & 0.08 \\
\hline \multicolumn{13}{|c|}{ Environmental Information Processing; Signaling molecules and interaction } \\
\hline 182 & cyclophilin-type peptidyl-prolyl cis-trans isomerase- 15 & 21545 & 5.95 & Mytilus galloprovincialis & FL494508 & 21737 & 5.77 & 305 & 6 & 28 & 1.22 & 0.26 \\
\hline 32 & dedicator of cytokinesis protein 8, partial, predicted & 61686 & 5.57 & Amphimedon queenslandica & gi|340379755 & 236465 & 6.29 & 53 & 2 & 2 & 0.68 & 0.06 \\
\hline 116 & G protein subunit beta- 1 & 34110 & 5.65 & Loligo forbesii & gi||121014 & 37983 & 5.76 & 403 & 9 & 34 & 1.12 & 0.08 \\
\hline
\end{tabular}


Table 1. Cont.

\begin{tabular}{c|c}
\hline $\mathbf{N}^{\mathbf{0}}$ & Name \\
\hline 162 & GTP-binding nuclear protein Ran, provisional \\
\hline 195 & peptidyl prolyl cis-trans isomerase A (II) \\
\hline 138 & receptor of Activated Kinase C 1 \\
\hline 139 & receptor of Activated Kinase C 1 \\
\hline 80 & receptor of Activated Kinase C 1 \\
\hline 31 & RIB43A-like with coiled-coils protein 2 \\
\hline 102 & serine/threonine-protein kinase pelle-like \\
\hline 124 & SET protein \\
\hline
\end{tabular}

\begin{tabular}{|c|c|c|c|c|c|c|c|c|c|c|c}
\hline Mr obs.pI obs. & species & access number & Mr calc.pI calc. & score & seq. & cov. & rel. Ab. & SD \\
\hline 25139 & 7.99 & Crassostrea gigas & gi|405971745 & 24274 & 6.96 & 72 & 2 & 10 & 3.01 & 0.32 \\
\hline 14887 & 8.55 & Conus novaehollandiae & gi|289064183 & 17759 & 7.68 & 178 & 4 & 20 & 6.17 & 0.75 \\
\hline 30251 & 6.96 & Mya arenaria & gi|115501910 & 35534 & 6.74 & 233 & 7 & 30 & 0.88 & 0.06 \\
\hline 30251 & 7.29 & Mya arenaria & gi|115501910 & 35534 & 6.74 & 662 & 15 & 58 & 2.24 & 0.10 \\
\hline 30251 & 7.41 & Mya arenaria & gi|115501910 & 35534 & 6.74 & 510 & 12 & 41 & 1.03 & 0.07 \\
\hline 46744 & 6.04 & Crassostrea gigas & gi|405963849 & 45583 & 6.09 & 124 & 4 & 5 & 1.64 & 0.34 \\
\hline 63776 & 5.44 & Bombus impatiens & gi|350396247 & 58945 & 8.87 & 54 & 1 & 1 & 1.01 & 0.10 \\
\hline 37354 & 4.49 & Crassostrea gigas & gi|405963180 & 28144 & 4.34 & 197 & 4 & 12 & 2.76 & 0.25 \\
\hline 32399 & 7.05 & Aplysia californica & gi|325197143 & 39468 & 9.03 & 117 & 2 & 6 & 0.82 & 0.07 \\
\hline
\end{tabular}

Cellular Processes; Transport and catabolism

\begin{tabular}{|c|c|c|c|c|c|c|c|c|c|c|c|c|}
\hline 181 & $\mathrm{C} 1 \mathrm{q}$ domain containing protein $\mathrm{MgC} 1 \mathrm{q} 64$, putative & 20473 & 5.85 & Mytilus galloprovincialis & gi|325504427 & 24551 & 8.32 & 65 & 2 & 20 & 0.85 & 0.09 \\
\hline 59 & catalase & 53914 & 7.99 & Mytilus californianus & gi|46909299 & 30345 & 6.01 & 235 & 7 & 34 & 1.31 & 0.28 \\
\hline 141 & cathepsin L-like, predicted & 27219 & 4.55 & Strongylocentrotus purpuratus & gi|115715524 & 37335 & 5.14 & 64 & 2 & 3 & 2.23 & 0.23 \\
\hline 16 & dipeptidyl peptidase family member 6 & 72142 & 5.68 & Crassostrea gigas & gi|405969597 & 74497 & 5.66 & 60 & 1 & 1 & 0.46 & 0.03 \\
\hline 134 & dyp-type peroxidase like & 30364 & 6.00 & Trichoplax adhaerens & gi|195996389 & 33144 & 6.21 & 59 & 2 & 6 & 1.03 & 0.11 \\
\hline 173 & glutathione S-transferase sigma 3 & 22964 & 5.56 & Mytilus galloprovincialis & gi|402227995 & 22940 & 5.44 & 121 & 3 & 18 & 0.65 & 0.06 \\
\hline 158 & glutathione S-transferase, Class Beta & 25489 & 6.57 & Mytilus californianus & ES392983 & 38159 & 5.76 & 74 & 2 & 8 & 1.96 & 0.15 \\
\hline 110 & heavy metal-binding protein HIP & 34810 & 4.92 & Mytilus edulis & gi|46395578 & 24388 & 5.09 & 165 & 6 & 45 & 2.43 & 0.38 \\
\hline 105 & kin 17-mid super family, hypothetical protein AND_04962 & 38721 & 6.53 & Anopheles darlingi & gi|312382372 & 48048 & 9.44 & 55 & 2 & 5 & 0.57 & 0.04 \\
\hline 58 & leucine aminopeptidase, predictive & 54915 & 8.03 & Mytilus californianus & ES400183 & 36649 & 7.01 & 332 & 8 & 40 & 2.32 & 0.25 \\
\hline 6 & major vault protein & 91110 & 5.48 & Mytilus edulis & gi|5714749 & 31855 & 5.45 & 343 & 9 & 46 & 0.50 & 0.07 \\
\hline 8 & major vault protein & 91892 & 5.55 & Mytilus edulis & gi|5714749 & 31855 & 5.45 & 718 & 16 & 56 & 1.27 & 0.12 \\
\hline 7 & major vault protein & 91892 & 5.53 & Crassostrea gigas & gi|405974681 & 96651 & 5.58 & 73 & 2 & 2 & 0.79 & 0.08 \\
\hline 9 & major vault protein & 90338 & 5.61 & Mytilus edulis & gi|5714749 & 31855 & 5.45 & 276 & 8 & 35 & 1.07 & 0.10 \\
\hline 170 & peroxiredoxin & 24186 & 6.7 & Pinctada fucata & gi|306451460 & 22530 & 7.63 & 99 & 2 & 9 & 1.81 & 0.23 \\
\hline 184 & peroxiredoxin $\mathrm{V}$ & 17924 & 6.38 & Chlamys farreri & gi|149688674 & 20431 & 8.20 & 69 & 1 & 5 & 4.55 & 0.24 \\
\hline 81 & Rab GDP dissociation inhibitor alpha & 45998 & 6.21 & Schistosoma japonicum & gi|226484726 & 50623 & 6.41 & 60 & 2 & 4 & 1.32 & 0.51 \\
\hline
\end{tabular}


Table 1. Cont.

\begin{tabular}{|c|c|c|c|c|c|c|c|c|c|c|c|c|}
\hline \multirow{2}{*}{\begin{tabular}{l|}
$\mathbf{N}^{\circ}$ \\
190 \\
\end{tabular}} & \multirow{2}{*}{$\begin{array}{c}\text { Name } \\
\text { superoxide dismutase }\end{array}$} & \multicolumn{2}{|c|}{ Mr obs.pI obs. } & \multirow{2}{*}{$\begin{array}{c}\text { species } \\
\text { Mytilus chilensis }\end{array}$} & \multirow{2}{*}{\begin{tabular}{|c|} 
access number \\
gi|332356353 \\
\end{tabular}} & \multicolumn{2}{|c|}{ Mr calc.pI calc } & \multirow{2}{*}{\begin{tabular}{|c|} 
score \\
173 \\
\end{tabular}} & \multicolumn{3}{|c|}{\begin{tabular}{|l|l|l|} 
seq. & cov. & rel. Ab. \\
\end{tabular}} & \multirow{2}{*}{\begin{tabular}{|c|} 
SD \\
0.18 \\
\end{tabular}} \\
\hline & & 14887 & 5.77 & & & 15925 & 5.84 & & 4 & 30 & 2.23 & \\
\hline 191 & superoxide dismutase $(\mathrm{Cu} / \mathrm{Zn}$-SOD) & 14673 & 6.11 & Mytilus edulis & gi|34481600 & 16046 & 5.84 & 289 & 4 & 31 & 3.40 & 0.22 \\
\hline 175 & superoxide dismutase, mitochondrial (Mn-SOD) & 22327 & 6.00 & Mytilus galloprovincialis & gi|402122769 & 25412 & 6.44 & 124 & 2 & 9 & 1.67 & 0.15 \\
\hline 203 & thioredoxin 1 & 12520 & 4.69 & Mytilus galloprovincialis & gi|391358072 & 11667 & 4.47 & 244 & 4 & 33 & 7.72 & 0.72 \\
\hline 178 & thioredoxin peroxidase & 23774 & 6.70 & Cristaria plicata & gi|306451460 & 22143 & 5.95 & 75 & 2 & 10 & 1.63 & 0.16 \\
\hline \begin{tabular}{l|l}
21 \\
\end{tabular} & V-type proton ATPase catalytic subunit A & 72142 & 5.45 & Crassostrea gigas & gi|405950221 & 71148 & 5.21 & 314 & 7 & 11 & 0.69 & 0.06 \\
\hline \multicolumn{13}{|c|}{ Cellular Processes; Cell motility; Cytoskeleton proteins } \\
\hline 92 & actin & 43011 & 5.60 & Mytilus sp. & gi|120564812 & 35392 & 5.26 & 93 & 3 & 14 & 0.90 & 0.10 \\
\hline 189 & actin & 15106 & 5.15 & Schistosoma japonicum & gi|257215973 & 10215 & 5.40 & 273 & 6 & 55 & 3.99 & 0.45 \\
\hline 196 & actin & 14330 & 5.05 & Hydroides elegans & gi|73532714 & 41520 & 5.39 & 357 & 9 & 19 & 2.90 & 0.28 \\
\hline 88 & actin $2=$ cytoplasmic actin $=$ beta actin & 42200 & 5.22 & Crassostrea gigas & gi|18565104 & 42002 & 5.30 & 669 & 15 & 47 & 5.83 & 0.44 \\
\hline 89 & actin $2=$ cytoplasmic actin $=$ beta actin & 42200 & 5.31 & Aedes aegypti & gi|67782283 & 42194 & 5.30 & 648 & 14 & 49 & 15.31 & 0.97 \\
\hline 91 & actin $2=$ cytoplasmic actin $=$ beta actin & 42200 & 5.4 & Mytilus sp. & gi|120564812 & 35392 & 5.26 & 454 & 11 & 51 & 1.86 & 0.13 \\
\hline 151 & actin $2=$ cytoplasmic actin $=$ beta actin & 26568 & 5.49 & Crassostrea gigas & gi|18565104 & 42002 & 5.30 & 444 & 11 & 32 & 3.25 & 0.23 \\
\hline 94 & $\operatorname{actin} 5$ & 40566 & 5.73 & Aedes aegypti & gi|67782283 & 42194 & 5.3 & 404 & 10 & 35 & 1.06 & 0.10 \\
\hline 150 & actin-87E isoform 1 , similar & 26845 & 5.28 & Tribolium castaneum & gi|91078486 & 42158 & 5.29 & 419 & 10 & 36 & 5.20 & 0.59 \\
\hline 2 & catchin protein & 113783 & 5.32 & Mytilus galloprovincialis & gi|6682323 & 112777 & 5.22 & 701 & 16 & 21 & 0.40 & 0.02 \\
\hline 179 & centrin-3 & 19785 & 4.66 & Crassostrea gigas & gi|405964350 & 20761 & 4.58 & 139 & 4 & 22 & 2.93 & 0.21 \\
\hline 192 & destrin, partial & 15330 & 6.38 & Macaca mulatta & gi|73696362 & 12274 & 8.64 & 64 & 2 & 7 & 7.79 & 0.54 \\
\hline 52 & fascin & 53914 & 6.01 & Crassostrea gigas & gi|405961655 & 56081 & 6.21 & 99 & 3 & 5 & 1.29 & 0.08 \\
\hline 53 & fascin-like domain protein & 53914 & 6.15 & Tetraodon nigroviridis & gi|47209051 & 106026 & 8.68 & 85 & 2 & 2 & 0.74 & 0.08 \\
\hline 78 & gelsolin & 46245 & 5.61 & Suberites domuncula & gi|27528508 & 42414 & 5.23 & 115 & 2 & 7 & 2.17 & 0.09 \\
\hline 194 & hypothetical protein KGM_09271 with pleckstrin homology-like domain & 14603 & 7.58 & Danaus plexippus & gi|357623784 & 110881 & 9.64 & 72 & 2 & 2 & 4.85 & 0.72 \\
\hline 29 & $\mathrm{Na}(+) / \mathrm{H}(+)$ exchange regulatory cofactor NHE-RF1 & 63335 & 4.83 & Mytilus galloprovincialis & FL501152 & 22127 & 4.93 & 347 & 6 & 42 & 1.39 & 0.37 \\
\hline 62 & non-neuronal cytoplasmic intermediate filament protein & 56303 & 5.27 & Mytilus californianus & GE750313 & 31541 & 7.63 & 410 & 9 & 29 & 2.03 & 0.27 \\
\hline 200 & profilin like & 12468 & 6.68 & Mytilus galloprovincialis & FL496207 & 20580 & 8.33 & 243 & 6 & 37 & 5.42 & 0.37 \\
\hline 117 & radial spoke head protein 9 , like & 32909 & 5.82 & Crassostrea gigas & gi|405959092 & 31220 & 5.20 & 118 & 3 & 8 & 1.21 & 0.22 \\
\hline
\end{tabular}


Table 1. Cont.

\begin{tabular}{|c|c|c|c|c|c|c|c|c|c|c|c|c|}
\hline \multirow{2}{*}{$\begin{array}{c}\mathbf{N}^{\circ} \\
1 \\
\end{array}$} & \multirow{2}{*}{$\begin{array}{c}\text { Name } \\
\text { spectrin alpha chain }\end{array}$} & \multicolumn{2}{|c|}{ Mr obs.pI obs. } & \multirow{2}{*}{$\begin{array}{c}\text { species } \\
\text { Crassostrea gigas }\end{array}$} & \multirow{2}{*}{\begin{tabular}{|l} 
access number \\
gi| 405973516 \\
\end{tabular}} & \multicolumn{2}{|c|}{ Mr calc.pI calc } & \multirow{2}{*}{\begin{tabular}{|l|} 
score \\
143 \\
\end{tabular}} & \multicolumn{3}{|c|}{\begin{tabular}{|l|l|l|} 
seq. & cov. & rel. Ab. \\
\end{tabular}} & \multirow{2}{*}{\begin{tabular}{|c|} 
SD \\
0.04
\end{tabular}} \\
\hline & & 105775 & 4.83 & & & 287684 & 4.88 & & 5 & 2 & 0.44 & \\
\hline 90 & tektin 1 & 45755 & 5.36 & Crassostrea gigas & gi|405975636 & 48654 & 6.12 & 55 & 2 & 3 & 1.86 & 0.12 \\
\hline 72 & tektin-2 & 49971 & 5.58 & Crassostrea gigas & gi|405950079 & 48059 & 5.71 & 172 & 6 & 18 & 2.60 & 0.14 \\
\hline 73 & tektin-4 & 48307 & 5.64 & Crassostrea gigas & gi|405967050 & 52952 & 5.53 & 172 & 7 & 12 & 2.72 & 0.18 \\
\hline 109 & tropomyosin & 35098 & 4.65 & Mytilus galloprovincialis & gi|6647862 & 32807 & 4.62 & 559 & 12 & 36 & 5.25 & 0.23 \\
\hline 126 & tropomyosin & 30478 & 4.69 & Mytilus edulis & gi|6647862 & 32836 & 4.64 & 312 & 6 & 12 & 1.81 & 0.13 \\
\hline 127 & tropomyosin & 30593 & 4.77 & Mytilus galloprovincialis & gi|6647862 & 32807 & 4.62 & 190 & 4 & 8 & 2.17 & 0.08 \\
\hline 49 & tubulin alpha-1 chain & 54915 & 5.09 & Schistosoma mansoni & gi|256087763 & 50660 & 4.97 & 780 & 18 & 47 & 11.21 & 0.75 \\
\hline 61 & tubulin beta chain & 51744 & 4.93 & Crassostrea gigas & gi|56603670 & 50371 & 4.79 & 705 & 15 & 37 & 31.68 & 1.30 \\
\hline 63 & tubulin, beta $2 \mathrm{C}$-like, predicted & 56303 & 5.40 & Saccoglossus kowalevskii & gi|291243365 & 50516 & 4.74 & 266 & 6 & 16 & 3.06 & 0.32 \\
\hline \multicolumn{13}{|c|}{ Unknown function } \\
\hline 35 & CCDC 151 like, coiled-coil domain containing 151 & 62469 & 6.68 & Crassostrea gigas & gi|405957528 & 63895 & 6.65 & 68 & 2 & 2 & 1.21 & 0.12 \\
\hline 50 & selenium-binding protein 1 , partial & 57755 & 5.48 & Crassostrea gigas & gi|405971621 & 54060 & 6.11 & 56 & 2 & 2 & 0.67 & 0.08 \\
\hline 201 & hypothetical protein AND_08398 & 12519 & 7.95 & Anopheles darlingi & gi|312379666 & 38819 & 8.84 & 53 & 2 & 0 & 4.58 & 0.55 \\
\hline
\end{tabular}


Table 2. Classification of the 203 proteoforms listed in Table 1 according to their coefficient of quartile variation (cqv in \%) indicating the spread in relative protein abundance obtained over five runs of 12 gels each $(n=60)$. See text for further explication.

\begin{tabular}{|c|c|c|c|}
\hline $\mathbf{N}^{\circ}$ & Proteoforme & cqv & \\
\hline 99 & isocitrate dehydrogenase & 5.9 & \multirow{21}{*}{$<10 \%$} \\
\hline 165 & fatty acid-binding protein, provisional & 6.7 & \\
\hline 72 & tektin-2 & 6.8 & \\
\hline 192 & destrin, partial & 7.4 & \\
\hline 78 & gelsolin & 7.7 & \\
\hline 73 & tektin-4 & 7.8 & \\
\hline 157 & triosephosphate isomerase, partial & 8.0 & \\
\hline 139 & receptor of Activated Kinase C 1 & 8.2 & \\
\hline 160 & Hadh2-prov protein isoform 1, similar & 8.3 & \\
\hline 23 & heat shock protein 70 & 8.4 & \\
\hline 60 & procollagen-proline dioxygenase beta subunit & 8.4 & \\
\hline 61 & tubulin beta chain & 8.9 & \\
\hline 109 & tropomyosin & 9.0 & \\
\hline 175 & superoxide dismutase, mitochondrial (Mn-SOD) & 9.1 & \\
\hline 68 & calreticulin, predicted & 9.1 & \\
\hline 119 & malate dehydrogenase, mitochondrial & 9.2 & \\
\hline 74 & enolase & 9.5 & \\
\hline 127 & tropomyosin & 9.5 & \\
\hline 156 & glyceraldehyde-3-phosphate dehydrogenase A (EC 1.2.1.12) & 9.6 & \\
\hline 104 & fructose-bisphosphate aldolase & 9.7 & \\
\hline 144 & Small heat shock protein 24.1 & 9.9 & \\
\hline 150 & actin-87E isoform 1, similar & 10.2 & \multirow{20}{*}{$<15 \%$} \\
\hline 105 & kin 17-mid super family, hypothetical protein AND_04962 & 10.2 & \\
\hline 115 & pur-alpha, putative & 10.3 & \\
\hline 93 & fructose-bisphosphate aldolase & 10.5 & \\
\hline 155 & enoyl-CoA hydratase, mitochondrial-like & 10.6 & \\
\hline 86 & $40 \mathrm{~S}$ ribosomal prot SA $(\mathrm{p} 40)(34 / 67 \mathrm{kDa}$ laminin receptor) & 10.7 & \\
\hline 143 & prohibitin & 10.9 & \\
\hline 142 & proteasome alpha 5 subunit-like & 11.0 & \\
\hline 16 & dipeptidyl peptidase family member 6 & 11.0 & \\
\hline 88 & actin $2=$ cytoplasmic actin $=$ beta actin & 11.0 & \\
\hline 95 & glutamine synthetase & 11.0 & \\
\hline 106 & cystathionine gamma-lyase & 11.0 & \\
\hline 118 & malate deshydrogenase, cytosolic & 11.0 & \\
\hline 138 & receptor of Activated Kinase C 1 & 11.0 & \\
\hline 122 & glyceraldehyde-3-phosphate dehydrogenase & 11.1 & \\
\hline 20 & heat shock cognate 71 & 11.1 & \\
\hline 136 & malate dehydrogenase, cytosolic & 11.5 & \\
\hline 89 & actin $2=$ cytoplasmic actin $=$ beta actin & 11.6 & \\
\hline 202 & histone H4 & 11.8 & \\
\hline 66 & ATP synthase alpha subunit mitochondrial & 11.9 & \\
\hline
\end{tabular}


Table 2. Cont

\begin{tabular}{|c|c|c|c|}
\hline $\mathbf{N}^{\circ}$ & Proteoforme & cqv & \\
\hline 168 & small $22 \mathrm{kd}$ heat shock protein, putative & 12.0 & \multirow{39}{*}{$<15 \%$} \\
\hline 30 & delta-1-pyrroline-5-carboxylate dehydrogenase, mitochondrial & 12.0 & \\
\hline 96 & 26S proteasome regulatory complex ATPase RPT4 & 12.0 & \\
\hline 185 & ribosomal protein rps13 & 12.2 & \\
\hline 70 & protein disulfide-isomerase, like & 12.2 & \\
\hline 82 & citrate synthase, mitochondrial, predicted & 12.4 & \\
\hline 52 & fascin & 12.4 & \\
\hline 35 & CCDC 151 like, coiled-coil domain containing 151 & 12.4 & \\
\hline 200 & profilin like & 12.5 & \\
\hline 152 & ETF beta-like & 12.5 & \\
\hline 184 & peroxiredoxin V & 12.6 & \\
\hline 135 & S-formylglutathione hydrolase & 12.7 & \\
\hline 116 & G protein subunit beta- 1 & 12.8 & \\
\hline 179 & centrin-3 & 12.8 & \\
\hline 55 & protein disulfide-isomerase, predicted & 12.9 & \\
\hline 108 & arginine kinase & 13.0 & \\
\hline 128 & 14-3-3 epsilon protein & 13.0 & \\
\hline 154 & enoyl-CoA hydratase, mitochondrial-like & 13.1 & \\
\hline 9 & major vault protein & 13.3 & \\
\hline 18 & EF-hand domain-containing protein 1 & 13.3 & \\
\hline 113 & pyruvate dehydrogenase E1 component subunit beta, mitochondrial & 13.3 & \\
\hline 203 & thioredoxin 1 & 13.3 & \\
\hline 186 & glucose-regulated protein 94 (fragment) & 13.4 & \\
\hline 141 & cathepsin L-like, predicted & 13.4 & \\
\hline 33 & TCP1, subunit beta-like & 13.4 & \\
\hline 85 & calumenin precursor, putative & 13.4 & \\
\hline 111 & inorganic pyrophosphatase-like & 13.6 & \\
\hline 147 & proteasome subunit alpha type- 4 & 13.6 & \\
\hline 114 & transcriptional activator protein pur-alpha & 13.6 & \\
\hline 53 & fascin-like domain protein & 13.7 & \\
\hline 191 & superoxide dismutase $(\mathrm{Cu} / \mathrm{Zn}-\mathrm{SOD})$ & 13.7 & \\
\hline 32 & dedicator of cytokinesis protein 8 , partial, predicted & 14.0 & \\
\hline 71 & elongation factor 1 alpha 1 & 14.0 & \\
\hline 129 & 14-3-3 epsilon ptotein & 14.2 & \\
\hline 183 & eIF5A like & 14.2 & \\
\hline 40 & TCP1, subunit theta & 14.3 & \\
\hline 13 & $78 \mathrm{kDa}$ glucose regulated protein & 14.4 & \\
\hline 126 & tropomyosin & 14.4 & \\
\hline 84 & phosphoglycerate kinase & 14.7 & \\
\hline 90 & tektin 1 & 15.0 & \multirow{4}{*}{$<20 \%$} \\
\hline 43 & TCP1, subunit eta-like isoform 1 & 15.1 & \\
\hline 130 & 14-3-3 epsilon protein & 15.1 & \\
\hline 91 & actin $2=$ cytoplasmic actin $=$ beta actin & 15.2 & \\
\hline
\end{tabular}


Table 2. Cont.

\begin{tabular}{|c|c|c|c|}
\hline $\mathbf{N}^{\circ}$ & Proteoforme & cqv & \\
\hline 25 & phenylalanyl-tRNA synthetase beta chain, probable & 15.2 & \\
\hline 190 & superoxide dismutase & 15.3 & \\
\hline 37 & NADPH-dependent aldehyde reductase, putative & 15.4 & \\
\hline & catchin protein & 15.4 & \\
\hline 159 & triosephosphate isomerase & 15.5 & \\
\hline 197 & histone $\mathrm{H} 2 \mathrm{~B}$ & 15.7 & \\
\hline 76 & $26 \mathrm{~S}$ protease regulatory subunit $6 \mathrm{a}$ RPT5 & 15.9 & \\
\hline 194 & hypothetical protein KGM_09271 with pleckstrin homology-like domain & 15.9 & \\
\hline 164 & NADH dehydrogenase [ubiquinone] iron-sulfur protein 8 , mitochondrial-like & 15.9 & \\
\hline 158 & glutathione S-transferase, Class Beta & 16.0 & \\
\hline 67 & NADH dehydrogenase (ubiquinone) flavoprotein 1 , mitochondrial & 16.0 & \\
\hline 140 & receptor of Activated Kinase C 1 & 16.0 & \\
\hline 62 & non-neuronal cytoplasmic intermediate filament protein & 16.1 & \\
\hline 188 & nucleoside diphosphate kinase & 16.1 & \\
\hline 87 & ATP synthase beta subunit & 16.2 & \\
\hline 151 & actin $2=$ cytoplasmic actin $=$ beta actin & 16.5 & \\
\hline 132 & small heat shock protein 24.1 & 16.6 & \\
\hline 107 & arginine kinase & 16.9 & \\
\hline 94 & actin 5 & 16.9 & \\
\hline 8 & major vault protein & 16.9 & $<20 \%$ \\
\hline 195 & peptidyl prolyl cis-trans isomerase A (II) & 16.9 & \\
\hline 4 & glucose-regulated protein 94 & 17.0 & \\
\hline 46 & PRP19/PSO4 pre-mRNA processing factor 19 homolog, predicted & 17.0 & \\
\hline 10 & aconitase 2, mitochondrial isoform 2, similar & 17.0 & \\
\hline & major vault protein & 17.1 & \\
\hline 121 & malate dehydrogenase, mitochondrial & 17.2 & \\
\hline 173 & glutathione S-transferase sigma 3 & 17.3 & \\
\hline 187 & tubulin-specific chaperone a-like & 17.4 & \\
\hline 65 & ATP synthase alpha subunit mitochondrial & 17.4 & \\
\hline 14 & NADH dehydrogenase subunit, hypothetical protein DAPPUDRAFT_192333 & 17.5 & \\
\hline 79 & fumarylacetoacetate hydrolase, similar & 17.5 & \\
\hline 64 & ATP synthase alpha subunit mitochondrial & 17.9 & \\
\hline 123 & 3-hydroxyanthranilate 3,4-dioxygenase & 17.9 & \\
\hline 117 & radial spoke head protein 9 , like & 17.9 & \\
\hline 153 & proteasome subunit alpha type- 6 & 18.0 & \\
\hline 59 & catalase & 18.1 & \\
\hline 80 & RIB43A-like with coiled-coils protein 2 & 18.2 & \\
\hline 189 & actin & 18.2 & \\
\hline 44 & TCP1, subunit gamma isoform 1 & 18.4 & \\
\hline
\end{tabular}


Table 2. Cont.

\begin{tabular}{|c|c|c|c|}
\hline $\mathbf{N}^{\circ}$ & Proteoforme & cqv & \\
\hline 100 & isocitrate dehydrogenase & 18.4 & \multirow{18}{*}{$<20 \%$} \\
\hline 48 & TCP1 subunit zeta & 18.4 & \\
\hline 171 & isocitrate dehydrogenase & 18.5 & \\
\hline 3 & glycine dehydrogenase & 18.5 & \\
\hline 177 & proteasome beta type- 6 subunit & 18.5 & \\
\hline 178 & thioredoxin peroxidase & 18.5 & \\
\hline 45 & TCP1, hypothetical protein & 18.7 & \\
\hline 131 & small heat shock protein 24.1 & 19.2 & \\
\hline 69 & $26 \mathrm{~S}$ proteasome regulatory subunit $\mathrm{T} 3$ & 19.3 & \\
\hline 21 & V-type proton ATPase catalytic subunit A & 19.3 & \\
\hline 133 & small heat shock protein 24.1 & 19.3 & \\
\hline 149 & voltage-dependent anion selective channel protein 2 , probable & 19.6 & \\
\hline 102 & SET protein & 19.6 & \\
\hline 12 & heat shock protein 90 & 19.6 & \\
\hline 41 & meiosis-specific nuclear structural protein 1-like & 19.7 & \\
\hline 148 & small heat shock protein 24.1 & 19.8 & \\
\hline 174 & calcyphosin-like protein & 19.8 & \\
\hline 198 & ribosomal protein S12 & 19.9 & \\
\hline 176 & ubiquination linked effector, hypothetical protein CRE_31518 & 20.0 & \multirow{23}{*}{$<25 \%$} \\
\hline 49 & tubulin alpha-1 chain & 20.2 & \\
\hline 17 & E3 ubiquitin-protein ligase TRIM33 & 20.3 & \\
\hline 103 & UDP-glucose 4-epimerase & 20.3 & \\
\hline 77 & 26S protease regulatory subunit 6a RPT5 & 20.4 & \\
\hline 19 & stress-70 protein, mitochondrial, predicted mortaline-like & 20.6 & \\
\hline 22 & succinate dehydrogenase (ubiquinone) flavoprotein subunit & 20.6 & \\
\hline 172 & glucosamine phosphate isomerase & 20.6 & \\
\hline 27 & phosphoenolpyruvate carboxykinase & 20.6 & \\
\hline 124 & sirtuin-5 & 20.6 & \\
\hline 15 & NADH-ubiquinone oxidoreductase $75 \mathrm{kDa}$ subunit, mitochondrial & 20.8 & \\
\hline 169 & proteasome alpha type 2 & 20.8 & \\
\hline 199 & ribosomal protein rps12 & 20.9 & \\
\hline 134 & dyp-type peroxidase like & 21.0 & \\
\hline 98 & isocitrate dehydrogenase & 21.0 & \\
\hline 47 & ubiquinone biosynthesis monooxygenase COQ6 & 21.0 & \\
\hline 29 & $\mathrm{Na}(+) / \mathrm{H}(+)$ exchange regulatory cofactor NHE-RF1 & 21.1 & \\
\hline 170 & peroxiredoxin & 21.1 & \\
\hline 196 & $\operatorname{actin}$ & 21.1 & \\
\hline 166 & putative small $22 \mathrm{kd}$ heat shock protein & 21.2 & \\
\hline 181 & C1q domain containing protein $\mathrm{MgC} 1 \mathrm{q} 64$, putative & 21.2 & \\
\hline 162 & GTP-binding nuclear protein Ran, provisional & 21.5 & \\
\hline 57 & amine oxidase, predicted & 21.5 & \\
\hline
\end{tabular}


Table 2. Cont.

\begin{tabular}{|c|c|c|c|}
\hline $\mathbf{N}^{\circ}$ & Proteoforme & $\mathbf{c q v}$ & \\
\hline 39 & heat shock protein 60 & 21.7 & \multirow{19}{*}{$<25 \%$} \\
\hline 31 & serine/threonine-protein kinase pelle-like & 21.8 & \\
\hline 56 & TCP1 subunit epsilon like, hypothetical protein SINV_10604 & 22.1 & \\
\hline 36 & transketolase & 22.1 & \\
\hline 97 & long-chain specific acyl-CoA dehydrogenase, mitochondrial precursor & 22.4 & \\
\hline 63 & tubulin, beta $2 \mathrm{C}$-like, predicted & 22.5 & \\
\hline 182 & cyclophilin-type peptidyl-prolyl cis-trans isomerase- 15 & 22.5 & \\
\hline 112 & short chain collagen $\mathrm{C} 4$, putative & 22.6 & \\
\hline 1 & spectrin alpha chain & 22.8 & \\
\hline 42 & UDP-N-acetylglucosamine pyrophosphorylase, provisional & 23.1 & \\
\hline 34 & UDP-N-acetylglucosamine pyrophosphorylase, provisional & 23.2 & \\
\hline 146 & endoplasmic reticulum protein ERp29 & 23.4 & \\
\hline 193 & ubiquinone biosynthesis monooxygenase COQ6 & 23.5 & \\
\hline 28 & phosphoenolpyruvate carboxykinase & 23.8 & \\
\hline 38 & chaperonin & 24.1 & \\
\hline 167 & ubiquinol-cytochrome c reductase, Rieske iron-sulfur polypeptide 1 & 24.1 & \\
\hline 58 & leucine aminopeptidase, predictive & 24.6 & \\
\hline 50 & selenium-binding protein 1 , partial & 24.7 & \\
\hline 5 & valosin-containing protein-like & 24.8 & \\
\hline 51 & elongation factor 1 alpha & 25.9 & \multirow{9}{*}{$<30 \%$} \\
\hline 137 & ribosomal protein $\mathrm{S} 2$ & 25.9 & \\
\hline 163 & phosphoglycerate mutase 1 & 25.9 & \\
\hline 92 & $\operatorname{actin}$ & 26.4 & \\
\hline 26 & phenylalanyl-tRNA synthetase beta chain, probable & 26.9 & \\
\hline 54 & dihydrolipoamide dehydrogenase & 27.1 & \\
\hline 101 & phosphoglycerate kinase & 27.6 & \\
\hline 201 & hypothetical protein AND_08398 & 27.7 & \\
\hline 125 & GDP-L-fucose synthetase & 28.0 & \\
\hline 145 & small heat shock protein 24.1 & 31.4 & \multirow{7}{*}{$>30 \%$} \\
\hline 24 & heat shock protein 70 & 33.5 & \\
\hline 81 & Rab GDP dissociation inhibitor alpha & 37.1 & \\
\hline 11 & aconitase 2 , mitochondrial isoform 2 , similar & 37.4 & \\
\hline 180 & translationally controlled tumour protein & 40.8 & \\
\hline 83 & succinate-semialdehyde dehydrogenase, mitochondrial & 43.8 & \\
\hline 75 & NFX1-type containing zinc finge, similar & 47.0 & \\
\hline
\end{tabular}

In the following sections, proteoforms that have yielded identification were grouped and will be discussed according to their principal cellular functions derived from the KEGG pathway classification as depicted in Figure 3. It becomes obvious, that a great number of the identified proteins either $(i)$ belong to the cytoskeleton; or (ii) are involved in protein synthesis and degradation; or (iii) have key functions in the energetic metabolism and cellular defence. Interestingly, several of these highly 
expressed proteins exhibit characteristics that reflect specificities of the organization and function of the mussel gill tissue.

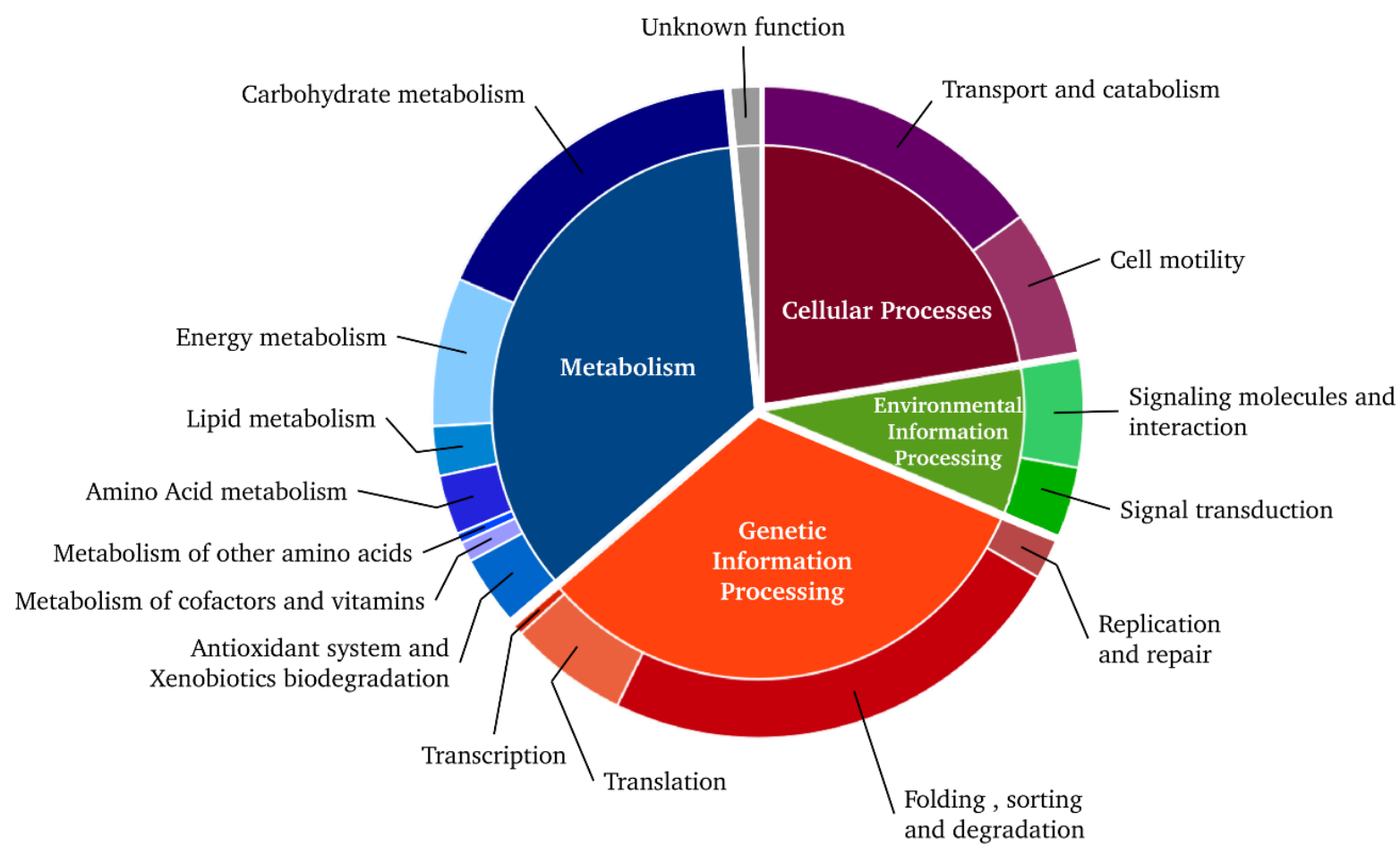

Figure 3. Functional classification of the 203 protein spots identified for Mytilus edulis gills according to their metabolic pathways and cellular functions (KEGG). Data derived from Table 1.

\subsection{Transcriptional and Translational Actors}

Classical ribosome-associated proteins are found abundantly in the blue mussel gill proteome (e.g., spot no. 25, 26, 86, 137, 185, 198 and 199). In addition, two ubiquitous and highly conserved translation factors were identified, namely, eukaryotic initiation factor 5A (eIF5A, spot no. 183) and eukaryotic elongation factor 1 alpha 1 (eEF1 $\alpha 1$, spot no. 71). Interestingly, the expression of these factors is redox sensitive $[66,67]$. The factor eEF1 $\alpha$ is one of the most abundant cytoplasmic proteins and is responsible for the binding of aminoacyl-tRNA to the ribosome in a GTP-dependent process [68]. It is also involved in the ubiquitination of proteins [69]. Interestingly, we identified the Pur-alpha protein (spot no. 114 and 115), a single-stranded DNA-binding protein implicated in the control of both DNA replication and gene transcription [70]. Pur-alpha may interact with E2F1, a DNA-binding transcription factor, which is known to play a role in ROS accumulation via the NF-kappa-B/MnSOD signal pathway related to oxidative stress [71].

\subsection{Cytoskeleton}

As expected from the structural organization of the mussel gills, characterised by ciliated filaments, actins and tubulins constitute the quantitatively most abundant proteins of this tissue (spot no. 49, 61, 89). Other cytoskeleton components are also well-represented as demonstrated by the identification of intermediate filament proteins (spot no. 2: catchin; spot no. 62: non-neuronal cytoplasmic intermediate 
filament protein) and a number of actin binding proteins (ABPs) (spot 1: spectrin; spot no. 52: fascin; spot no. 78: gelsolin; spots no. 109, no. 126 and 127: tropomyosin; spot no. 192: destrin; spot no. 200: profiling-like; spot no. 194: pleckstrin-like). Among them, notably non-muscular tropomyosins are involved in a range of cellular functions that control and regulate the cells cytoskeleton. Studies suggest that the binding of tropomyosin isoforms to an actin filament may influence the binding of other ABPs, which together alter the structure and endow specific properties and functions to an actin filament [72]. Among them, profilin (spot no. 200) is an ABP involved in the dynamic turnover and restructuring of the actin cytoskeleton. Gelsolin (spot no. 78) acts also as a key regulator of actin filament assembly and disassembly. Numerous other identified proteins also potentially interact with the actin and tubulin networks. For example, the dedicator of cytokinesis 8 (spot no. 32) is implicated in the regulation of the actin cytoskeleton. Proteins containing long coiled-coil domains like the RIB43A-like with coiled-coils protein 2 (spot no. 80) are involved in tying other proteins to solid-state components of the cell [73].

Several protein identifications point to the particular nature of a ciliated epithelial structure, which is characterized by a specific organisation of actin microfilaments and tubulin microtubules. Tektins (spot no. 72, 73 and no. 90) are cytoskeletal proteins found in cilia and flagella as structural components of outer doublet microtubules. Radial spoke head proteins 9 (spot no. 117) are involved in the movement of cilia and consist of $(i)$ a thin stalk, which is attached to a subfiber of the outer doublet microtubule, and (ii) a bulbous head, which is attached to the stalk and interacts with the projections from the central pair of microtubules [74]. The $\mathrm{Na}(+) \mathrm{H}(+)$ exchange regulatory cofactor NHE-RF1 (spot no. 29), also named Ezrin-radixin-moesin (ERM)-binding phosphoprotein 50, helps to link members of the ERM family to the actin cytoskeleton as well as to regulate their surface expression. The ERM proteins are highly concentrated in the apical part of polarized epithelial cells and are thought to be linkers between integral membrane and cytoskeletal proteins [75]. We also identified SET (spot no. 102), a phosphatase inhibitor 2, which is a multifunctional protein that, amongst other functions, regulates the microtubule networks of cilia. For instance, in primary cilia of human renal epithelium cells, endogenous phosphatase inhibitor 2 was found to be highly expressed and involved in the early formation of cilia [76].

\subsection{Energetic, Carbohydrate and Amino Acid Metabolisms}

The relatively high number of mitochondrial proteins related to energetic metabolism is consistent with the supposedly high energetic demand of gill tissue, which is engaged in water movement and transport of food particles. Also, osmoregulatory ion-transport via the gill epithelia is likely to be coupled to oxidative metabolism [77,78]. Furthermore, the function of chaperones and the proteasome (see sections below) depend on ATP-cycling [79,80]. Major carbohydrate metabolic pathways are represented by six enzymes of the tricarboxylic acid cycle (spot no. 11, 54, 82, 100, 113 and 119) and numerous enzymes of the oxidative phosphorylation process (for example, spot no. 66: ATP synthase alpha subunit; spot no. 87: ATP synthase beta subunit; spot no. 14: NADH dehydrogenase subunit). Glycolytic enzymes of the cytosol are also well represented with nine enzymes implied in glycolysis/neoglucogenesis. A prominent example is that of arginine kinase (spot no. 107 and 108), which plays an important role in the generation of ATP in invertebrates when a rapid energy supply is necessary [81-83].

One of the most characteristic features of the gill proteome, are the enzymes belonging to the amino acid and amino sugar pathways (spot no. 34, 42, 79, 103, 125 and 172), which are of great importance 
not only for the anabolism of the mussel but also for its osmotic integrity. Blue mussels are osmoconformers, which means that osmotic pressure and ionic composition of the haemolymph closely matches that of the salt or brackish water of their habitats. In addition to classical inorganic ions, such as sodium and chloride, highly soluble amino acids are used as intra-cellular osmotic buffer [84]. During hypertonic stress, the accumulation of intracellular alanine requires an inhibition of the pyruvate dehydrogenase complex (spot no. 113) in order to shunt mitochondrial pyruvate towards alanine and a high activity of the cytosolic malate dehydrogenase enzyme (spot no. 136) to maintain the cytosolic redox balance [85]. These metabolic processes are also involved in resistance to hypoxia during prolonged emersion [86]. The V-type proton ATPase catalytic subunit (spot no. 21) may also be related to ionic regulation via the gill epithelia, since V-type proton ATPase contributes to the buffering of the hypoxia-induced acidosis through the exchange of $\mathrm{H}^{+} / \mathrm{Ca}^{2+}$ during water deficiency [87]. Furthermore, low tide emersion usually signifies cessation of foraging; the animals usually pass this period fasting and in metabolic depression. Among proteins involved in homeostasis, Sirtuin 5 (spot no. 124) activates the mitochondrial carbamoyl-phosphate synthase through desuccinylation and thereby contributes to the regulation of blood ammonia levels during prolonged fasting. Sirtuins have been also shown to induce protein deacetylation, thus affecting the heat shock response in blue mussel congeners [14].

\subsection{Antioxidant and Defence Systems}

Gills constitute a privileged interface with the external medium and therefore gill epithelia comprise one of the first lines of defence against pathogens, xenobiotics and other environmental stressors. Consistently, several proteins belonging to the innate immune system have been identified such as spot no. 181 (C1q domain containing protein $\mathrm{MgC1q} 64$, putative) and no. 141 (cathepsin L, predicted). C1q domain containing proteins act through the recognition of pathogen associated molecular patterns (PAMPs) and possibly have an opsonin function [88,89]. The C1q domain is also present in heavy metal binding HIP (spot no. 110), which also has been detected in gills of clams [90]. Besides, haemocytes of Ruditapes decussatus subjected to bacterial challenge showed up-regulation of EST transcripts sharing similarities with this protein, highlighting a possible role in the immune defence [91]. On the other hand, the binding of divalent metal cations probably constitutes the major function of these proteins in gills, where they could contribute to metal detoxification processes.

Heavy metals, but also transition metals and organic compounds, which mussels are likely to encounter, notably in polluted habitats, are responsible for cellular oxidative stress through depletion in molecular thiol-containing antioxidants, catalysis of redox reactions and metabolism-induced bioactivation, respectively $[92,93]$. Life in the intertidal zone is also associated with hypoxia during emersion at low tide and reperfusion of oxygen in the initial reimmersion phase resulting in oxidative stress, which, in turn, will induce the antioxidant defence. For instance, the tyrosine 3-monooxygenase/tryptophan 5-monooxygenases, also named 14-3-3 epsilon proteins (spot no. 128, 129 and 130), play a central role in the regulation of signal transduction associated with the cellular redox status. During hypoxia they translocate into the nucleus and interact with the c-Jun N-terminal kinase (JNK) during oxidative stress [94]. Also, several enzymes that are involved in redox balance control were identified: catalase (spot no. 59); unspecified-Cu/Zn- and Mn-superoxide dismutases (SOD) (spot no. 175, 190 and 191); dyp-type and thioredoxine peroxidases: thioredoxin 1 (spot no. 203); thioredoxin peroxidase (spot 
no. 178); peroxiredoxin proteins (spot no. 170 and 184); sigma and beta glutathione transferases (GSTs) (spot no. 158 and 173). Catalase and SOD constitute the main antioxidant enzymes, which catalyse the reduction of reactive oxygenated species. Their activities are highly modulated in Mytilus spp. gills in response to different adverse environmental conditions [10,95-97]. Likewise, peroxiredoxins, peroxidases and, indirectly, thioredoxin participate in the reduction of $\mathrm{H}_{2} \mathrm{O}_{2}$ and other organic peroxides. Moreover, thioredoxin peroxidase could be involved in transcriptional induction of thioredoxin-system components in response to oxidative stress [98]. Thiol oxidoreduction reactions are crucial to cellular antioxidant processes and, together with glutathione metabolism, form a faculty, which is critical in a tissue subjected to frequent oxidative stress. The expression of two classes of GSTs (spot no. 158 and 173) in mussel gills is in agreement with this statement. GSTs, which are involved in the second phase of organic xenobiotic metabolisation (glutathione conjugation), can display peroxidase activity as well and exhibit particularly high levels of total activity in M. edulis gills [99,100].

\subsection{Protein Stabilisation, Folding and Sequestration}

Chaperones are multifunctional proteins, which assist protein folding and sorting [101-103], and are involved in various cellular processes such as growth, differentiation, and apoptosis. Heat shock proteins (Hsps) of the various families (small Hsp-, Hsp60-, Hsp70- and Hsp90-family) and their respective cognate forms (heat shock cognates, Hscs) belong to the most abundant cytosolic proteins. Their extensive presence in the gill proteome of $M$. edulis may be partly explained by the exigencies imposed to the gill tissue through the varying external physico-chemical conditions like salinity/osmolarity, temperature and/or desiccation. Stressors, such as oxidative stress and temperature changes, may induce cellular chaperones or heat shock proteins (Hsps) and elevated levels of these proteins help the animals to resist adverse environmental conditions by stabilising damaged proteins, which then may either be refolded or subjected to ubiquitin-mediated degradation by the proteasome (see next section). Thus, not surprisingly, Hsps and Hscs were particularly well represented in the mussel gill proteome (17\% of the identified proteins). The classical protein extraction protocol using mechanical homogenisation, sonication and high molar urea releases a variety of stress proteins, notably of the Hsp70-family, which originate from different cellular compartments, such as the cytosol, nucleus, mitochondria or endoplasmatic reticulum (ER). This becomes particularly obvious in the $78 \mathrm{kDa}$ and $94 \mathrm{kDa}$ glucose regulated protein (spot no. 13 and 4), as well as other chaperones from the ER, like calreticulin (spot no. 68), endoplasmic reticulum protein ERp29 (spot no. 146) and the protein disulfide-isomerases (spot no. 55 and 70). Other Hsps are typically found in the mitochondria, e.g., Hsp60 (spot no. 39). The majority of the Hsps, however, probably represent cytosolic forms (spot no. 23 and 24: Hsp70; spot no. 20: Hsc71; spot no. 12: Hsp90; spot no. 166 and 168: small Hsp 22; spot no. 131-133, 144, 145 and 148: small Hsp 24.1).

The family of small Hsps (sHsps) comprises a suite of chaperones with variable $\mathrm{Mr}$, ranging from about $15-30 \mathrm{kDa}$ (average $\mathrm{Mr} c a .17 .9 \mathrm{kDa}$ ). They consist of monomeric or dimeric subunits that are composed of a conserved " $\alpha$-crystallin" domain and variable $N$ - and $C$-terminal regions [104]. This basic primary sHsp structure may be complemented with a "middle domain" or additional $\alpha$-crystallin domains. The mono- or dimeric building blocks assemble into highly dynamic oligo- to multimeric polyhedrons (12mer-48mer) with molecular masses exceeding $200 \mathrm{kDa}$. The degree of oligomerisation and the exchange of subunits may depend on thermal or other environmental stresses [105]. sHsps often carry 
PTMs on the $N$-terminal region [104]; also here the phosphorylation status may determine chaperone activity and affect cellular distribution (reviewed in [105]). In addition, the subunits recovered from 2-DE gels may frequently be truncated of their terminal regions [104]. Hence, it is not surprising that identifications can be obtained for sHsp-proteoforms at various $\mathrm{Mr}$ and $\mathrm{pI}$. Although their functional role is less studied than that of the Hsp70- or Hsp90-families [106], their response to thermal and other types of environmental, physiological and pathological stresses is well known [107]. Generally, they are considered as "holdases" that stabilise nascent or damaged proteins, thus preventing their aggregation [104] until the "foldases", such as Hsp70 and Hsp90 assure (re-)folding of the destabilised proteins or direct them to degradation by the proteasome [45,108]. This function as holdase becomes particularly important whilst emersion during ebb occurs when the mussels' depressed metabolism does not allow for excessive production of foldases, notably Hsp70. Furthermore, sHsps could have an important role in protecting proteins from oxidative stress that will inevitably occur when reimmersed during rising tide [49].

The Hsp70-family is by far the best-investigated and most eminent class of chaperones, being highly conserved across all domains of life. Several isoforms fulfil different cellular functions, with Hsc70 occupying a central role in chaperone-mediated protein folding [101]. Its inducible counterpart Hsp70 is one of the major stress-proteins and responds particularly to thermal stimuli but also to many other abiotic and biotic stressors [109,110]. Hsp70 appears to be a key-player, notably in fluctuating environments where its inducibility appears to be much higher than in more stable conditions [111-113]. Also, high numbers of Hsp70 genes were found in the oyster genome, probably reflecting the adaptation to harsh changes in the intertidal environment [2]. Interestingly, the gene structure of the promoter region of Hsps in organisms inhabiting fluctuating environments with regular exposure to abiotic stresses appears to be highly complex, as demonstrated by Pantzartzi et al. [12]. It is very likely that this complexity reflects the presence of various response elements that allow for a fine tuned and differential regulation of the numerous Hsps according to the respective stressor. For instance, specific regulation of Hsp70 isoforms in roots of Musa spp. through osmotic stress could be related to a specific abscisic acid response element present in the promoter region of some isoforms but not in others [114]. Hsp70s of $M$. edulis appeared in horizontally adjoining spots (of which spots no. 23 and 24 have been identified), being indicative of PTMs. $C$-terminal phosphorylation of Hsp70, which is supposed to regulate co-chaperone binding that changes Hsp70-function between folding and directing proteins for degradation [45], would be one possible explanation for this observation.

Hsps of the $90 \mathrm{kDa}$-family assist in ATP-dependant protein folding, whereby some Hsp90 closely interact with Hsc70, a cooperation coordinated by a number of co-chaperones that regulate Hsc70/Hsp90 activity through ATPase cycling and substrate exchange, thus forming a "multichaperone machinery" [101]. Hsp90 also mediates stress signal transduction via protein kinases and transcription factors through which stress inducible genes can be regulated $[115,116]$. In fact, proteotoxic stresses are less likely to change overall Hsp90 levels [117], but rather act through release of heat shock transcription factors that activate gene-expression via the heat shock response elements in the promoter regions of stress responsive genes [118]. Hsp90 may also regulate stress responses via MAP kinase signalling, which, for instance, may lead to cell wall modifications [118]. 


\subsection{Intracellular Protein Trafficking}

The t-complex protein 1 (TCP1), of which most of all subunits belonging to its functional ring could be identified (spot no. 33, 40, 43-45, 48 and 56) may be particularly representative of the intracellular transport of proteins. TCP1, also known as the TCP1 ring complex (TRiC), consists of two identical stacked rings, each containing eight different proteins. Although TCP1 belongs to the cytosolic compartment, where it assists the folding of proteins upon ATP hydrolysis, it may also be involved in the assembly of the BBSome, a complex participating in ciliogenesis, by regulating transport vesicles to the cilia. Organisation of the cilium as an extracytoplasmic organelle requires vesicular trafficking; a process modulated by small GTPases of the Rab- and Arf-families and which uses microtubule-dependent motor proteins to mobilize ciliary cargo [119]. Hence, TCP1 is likely to be an important component of cilia formation, an obviously eminent process in an organ that possesses a large amount of cilia such as gills.

The abundance of major vault protein (spot no. 6-9) most likely also relates to specificities of the gill structure. Briefly, vaults are multi-subunit structures that consist in huge cage structures of $12.9 \mathrm{mDa}$ formed by dimers of half-vaults. Each half-vault comprises 39 identical major vault proteins of $110 \mathrm{kDa}$, PARP4 and one or several vault RNAs, small RNA species of 140 nucleotides that are involved in nucleo-cytoplasmic transport as well as in multiple cellular processes. Higher expression of vaults has been observed in epithelial cells with secretory and excretory functions, as well as in cells chronically exposed to xenobiotics, such as bronchial cells. In humans, the phosphorylated protein interacts with the $\mathrm{SH} 2$ domains of proteins, modulating their effects [43].

\subsection{Ubiquitin Proteasome System}

The Ubiquitin Proteasome System (UPS; [120]) was well represented in the M. edulis gill proteome, with a total of 12 spots identified. Although detailed information concerning the role of UPS in the gills of bivalves remains scarce [121], several proteosomal components have been repeatedly detected in earlier "omics" studies on bivalves [14,122,123]. The UPS is a highly conserved system responsible for cell clearance of abnormal, damaged proteins or those that are no longer of physiological relevance in the cell. Thus, the UPS constitutes the main cellular system implied in controlled protein degradation. Briefly, proteins targeted for degradation are first labelled with polyubiquitin tags through a three-step cascade, and then recognized, unfold and finally cleaved into short peptides by the 26S proteasome.

Ubiquitination requires the sequential action of three types of enzymes: ubiquitin is first activated by E1, then transferred to E2 ubiquitin-conjugating enzyme and finally, an E3 ubiquitin-ligase attaches the ubiquitin moiety to the substrate. Spot 17 corresponds to Tripartite Motif containing protein 33 (TRIM33) also known as TIF1 $\gamma$, a nuclear RING-based E3 ligase. It is implicated in regulation of TGF- $\beta$ pathway through promoting ubiquitination of smad4 [124]. More recently, Kulkarni et al. [125] demonstrated that TRIM33 is involved in double strand break response.

The 26S proteasome consists of a 20S catalytic core particle linked to one or two 19S regulator complexes containing regulatory proteins (RP) [126,127]. The proteolytic core is a barrel-shaped complex composed of two external rings of seven $\alpha$-subunits $(\alpha 1-\alpha 7)$ that embrace two inner rings of seven $\beta$-subunits $(\beta 1-\beta 7)$. The $\alpha$-rings regulate the entry into the catalytic chamber through their conserved $N$-terminal extensions [128]. We identified five spots corresponding to the 20S proteasome: spots no. 169, 
147, 142 and 153 were identified as subunits $\alpha 2, \alpha 4, \alpha 5$ and $\alpha 6$, respectively, and spot no. 177 corresponded to a non-active $\beta$-subunit, namely $\beta 6$, implied in the maturation of the three active $\beta$-subunits, which carry proteolytic activities $[129,130]$. Alternative forms of the proteasome have been described for jawed vertebrates (i.e., the immunoproteasome, [126]), in which variants of three of the $\beta$-subunits replace the classical ones of the $20 \mathrm{~S}$ core. Apparently, such $\beta$-subunits are restricted to vertebrates, as none of these alternative subunits was identified in our gill proteome.

The 19S RP can be dissociated into a lid and a base covered by the lid. We identified a single subunit from the lid: RPN11 (spot no. 120), which is a deubiquitinating enzyme (DUB) and belongs to the metalloenzyme JAMM-family. It appears to promote substrate degradation through cutting at the base of the polyubiquitin chain [131]. Recently, it has been suggested that RPN11 could be implicated in response to double stand breaks in mammals [132]. The base of RPN11 consists of six ATPase and four non-ATPase subunits and is involved in recognition, unfolding and translocation of protein into the core particle. Spots no. 69 and 96 correspond to the ATPase subunits RTP3 and RTP4, respectively, and spots no. 76 and 77 were identified as RTP5, an ATPase subunit specifically implied in the recognition of the polyubiquitylated substrate [133].

\section{Conclusions}

The data presented in this study extend our knowledge of the M. edulis gill proteome. Despite a weak representation of this species in gene and protein databases, we were able to identify more than 100 proteins and more than 200 proteoforms present in the mussel gill tissue. Although many of the identified proteins are of ubiquitous nature, which also explains their abundance, many of the functional groups to which they could be attributed display plausible relations to the general stress response, the distinctive structural features of the gill tissue and the metabolic demands of a highly dynamic environment: the main characteristics of gill organization and physiology are indeed underscored by an important representation of cytoskeleton, metabolism and defence related proteins, thus validating the protein identifications. The equivalence of this proteome inventory to those described by Tomanek and Zuzow [14] and Fields et al. [36] validates the importance of many of these proteins for a life in harsh environmental conditions. Identification and knowledge about the proteoforms being the first step, quantitative proteomics, investigating condition-related alterations of the proteome, will benefit from a thorough and comprehensive mapping of the proteome constituents (see for instance [134,135]) and, particularly, from the knowledge on protein species from the same protein [54]. In this respect, also the reproducibility of proteoforms, i.e., the dispersion of their relative abundance among replicate gels, is important information. Several implications arise from the inventory presented here: firstly, a large number of stress-related proteins can be identified and localised simultaneously with some experience on 2-DE gels, allowing for characterisation of complex protein networks and their perturbations. Proteomics, potentially, enables a more comprehensive view on particular response-complexes such as oxidative stress- and Hsp-networks or the proteasome [136]. Alterations of specific protagonists within these complexes may deliver more detailed information about the underlying molecular mechanisms, and quantitative changes, rather than focussing on one particular marker protein or conducting several independent assays. Secondly, measures of total protein, for instance using an immunoassay, may indicate elevated protein levels which, however, may comprise an ill-defined amount of non-functional protein (e.g., truncated 
forms or PTMs that inhibit protein activity). Indeed, McDonagh and Sheehan [137] demonstrated increased carbonylation and ubiquination of proteins in response to oxidative stress, pointing to irreversible protein damage [137]. But oxidative stress may also change the redox status of proteins, with protein oxidation representing an important regulatory modification [138]. Proteins for which deviations from their expected PI and Mr were also detected in this study, such as $\beta$-tubulin (spot 61), calreticulin (spot 68), protein disulphide-isomerase (spot 68), enolase (spot 74), gelsolin (spot 78) and heavy metal-binding protein (spot 110) were found to be oxidised by the model pro-oxidant menadione, leading to the reduction of free thiols and an increase of disulphides [138]. Thus, close examination of the different proteoforms displayed on 2-DE gels and their quantitative changes could reveal the precise nature of protein accumulation and modification following changes of the environmental conditions or exposure to toxic compounds, thus providing an in depth examination of the stress responses. Indeed, one of the strengths of the gel-based proteomics approach is the potential for analysing various PTMs associated with different states of the animal and its surrounding environment. Albeit being a complicated endeavour, examination of putative PTMs should be given more weight as this could provide supplementary and more far reaching information for the interpretation of the complexity of stress responses, which help these animals to cope with their ever changing environment and to fight parasite infestation or exposure to man-made chemicals. Our increasingly comprehensive catalogue of mussel gill proteins represents a valuable resource for future studies of responses to environmental and anthropogenic stresses in Mytilus spp.

\section{Acknowledgments}

This research received funding from CNRS-INSU through the DECIME project as well as from the European Regional Development Fund via ECORSA and from the region Haute-Normandie by SCALE Fesel. R.P. is supported by a doctoral fellowship from the Communauté de l'Agglomération Havraise (CODAH).

\section{Author Contributions}

B.R., F.B. and J.L. were responsible for the conception of the study; B.R., J.L., S.O., A.P. performed sample preparation and gel analysis; P.C. and D.V. were responsible for mass spectrometry analyses; P.C., B.R., F.B., R.P. performed data analyses; B.R., F.B., F.LF., J.L., T.M. and T.K. wrote or contributed to the writing of the manuscript; figures and tables were prepared by B.R., F.B., R.P. and T.K. All authors read and approved the final version of the manuscript.

\section{Conflicts of Interest}

The authors declare no conflict of interest.

\section{References}

1. Odronitz, F.; Hellkamp, M.; Kollmar, M. diArk-A resource for eukaryotic genome research. BMC Genomics 2007, 8, e103. 
2. Zhang, G.; Fang, X.; Guo, X.; Li, L.; Luo, R.; Xu, F.; Yang, P.; Zhang, L.; Wang, X.; Qi, H.; et al. The oyster genome reveals stress adaptation and complexity of shell formation. Nature 2012, 490, 49-54.

3. Knigge, T.; Monsinjon, T.; Andersen, O.K. Surface-enhanced laser desorption/ionization-time of flight-mass spectrometry approach to biomarker discovery in blue mussels (Mytilus edulis) exposed to polyaromatic hydrocarbons and heavy metals under field conditions. Proteomics 2004, 4, 2722-2727.

4. Manduzio, H.; Cosette, P.; Gricourt, L.; Jouenne, T.; Lenz, C.; Andersen, O.K.; Leboulenger, F.; Rocher, B. Proteome modifications of blue mussel (Mytilus edulis L.) gills as an effect of water pollution. Proteomics 2005, 5, 4958-4963.

5. Venier, P.; de Pitta, C.; Bernante, F.; Varotto, L.; de Nardi, B.; Bovo, G.; Roch, P.; Novoa, B.; Figueras, A.; Pallavicini, A.; et al. MytiBase: A knowledgebase of mussel (M. galloprovincialis) transcribed sequences. BMC Genomics 2009, 10, e72.

6. Goldberg, E.D.; Bowen, V.T.; Farrington, J.W.; Harvey, G.; Martin, J.H.; Parker, P.L.; Risebrough, R.W.; Robertson, W.; Schneider, E.; Gamble, E. The Mussel Watch. Environ. Conserv. 1978, 5, 101-125.

7. Connor, K.M.; Gracey, A.Y. Circadian cycles are the dominant transcriptional rhythm in the intertidal mussel Mytilus californianus. Proc. Natl. Acad. Sci. USA 2011, 108, 16110-16115.

8. Place, S.P.; Menge, B.A.; Hofmann, G.E. Transcriptome profiles link environmental variation and physiological response of Mytilus californianus between Pacific tides. Funct. Ecol. 2012, 26, 144-155.

9. Schneider, K.R. Heat stress in the intertidal: Comparing survival and growth of an invasive and native mussel under a variety of thermal conditions. Biol. Bull. 2008, 215, 253-264.

10. Letendre, J.; Chouquet, B.; Rocher, B.; Manduzio, H.; Leboulenger, F.; Durand, F. Differential pattern of $\mathrm{Cu} / \mathrm{Zn}$ superoxide dismutase isoforms in relation to tidal spatio-temporal changes in the blue mussel Mytilus edulis. Comp. Biochem. Physiol. Part C Toxicol. Pharmacol. 2008, 148, 211-216.

11. Letendre, J.; Dupont-Rouzeyrol, M.; Hanquet, A.C.; Durand, F.; Budzinski, H.; Chan, P.; Vaudry, D.; Rocher, B. Impact of toxicant exposure on the proteomic response to intertidal condition in Mytilus edulis. Comp. Biochem. Physiol. Part D Genomics Proteomics 2011, 6, 357-369.

12. Pantzartzi, C.; Drosopoulou, E.; Yiangou, M.; Drozdov, I.; Tsoka, S.; Ouzounis, C.A.; Scouras, Z.G. Promoter complexity and tissue-specific expression of stress response components in Mytilus galloprovincialis, a sessile marine invertebrate species. PLoS Comput. Biol. 2010, 6, e1000847.

13. Olsson, B.; Bradley, B.P.; Gilek, M.; Reimer, O.; Shepard, J.L.; Tedengren, M. Physiological and proteomic responses in Mytilus edulis exposed to PCBs and PAHs extracted from Baltic Sea sediments. Hydrobiologia 2004, 514, 15-27.

14. Tomanek, L.; Zuzow, M.J. The proteomic response of the mussel congeners Mytilus galloprovincialis and $M$. trossulus to acute heat stress: Implications for thermal tolerance limits and metabolic costs of thermal stress. J. Exp. Biol. 2010, 213, 3559-3574.

15. Dowd, W.W.; Somero, G.N. Behavior and survival of Mytilus congeners following episodes of elevated body temperature in air and seawater. J. Exp. Biol. 2013, 216, 502-514.

16. Dutton, J.M.; Hofmann, G.E. Spatial and temporal variation in distribution and protein ubiquitination for Mytilus congeners in the California hybrid zone. Arine Biol. 2008, 154, 1067-1075. 
17. Tomanek, L. Proteomics to study adaptations in marine organisms to environmental stress. J. Proteomics 2014, 105C, 92-106.

18. Suchanek, T.H.; Geller, G.B.; Kreiser, B.R.; Mitton, J.B. Zoogeographic Distributions of the Sibling Species Mytilus galloprovincialis and M. trossulus (Bivalvia: Mytilidae) and Their Hybrids in the North Pacific. Biol. Bull. 1997, 193, 187-194.

19. Rawson, P.D.; Hilbish, T.J. Asymmetric introgression of mtDNA among European populations of blue mussels (Mytilus spp.). Evolution 1998, 52, 100-108.

20. Westfall, K.M.; Gardner, J.P. Genetic diversity of Southern hemisphere blue mussels (Bivalvia: Mytilidae) and the identification of non-indigenous taxa. Biol. J. Linn. Soc. 2010, 101, 898-909.

21. Lopez, J.L.; Marina, A.; Alvarez, G.; Vazquez, J. Application of proteomics for fast identification of species-specific peptides from marine species. Proteomics 2002, 2, 1658-1665.

22. Lopez, J.L.; Abalde, S.L.; Fuentes, J. Proteomic approach to probe for larval proteins of the mussel Mytilus galloprovincialis. Mar. Biotechnol. (N.Y.) 2005, 7, 396-404.

23. Tomanek, L. Environmental proteomics of the mussel Mytilus: Implications for tolerance to stress and change in limits of biogeographic ranges in response to climate change. Integr. Comp. Biol. 2012, 52, 648-664.

24. Diz, A.P.; Dudley, E.; Cogswell, A.; MacDonald, B.W.; Kenchington, E.L.; Zouros, E.; Skibinski, D.O. Proteomic analysis of eggs from Mytilus edulis females differing in mitochondrial DNA transmission mode. Mol. Cell Proteomics 2013, 12, 3068-3080.

25. Diz, A.P.; Skibinski, D.O. Evolution of 2-DE protein patterns in a mussel hybrid zone. Proteomics 2007, 7, 2111-2120.

26. Suarez-Ulloa, V.; Fernandez-Tajes, J.; Manfrin, C.; Gerdol, M.; Venier, P.; Eirin-Lopez, J.M. Bivalve omics: State of the art and potential applications for the biomonitoring of harmful marine compounds. Mar. Drugs 2013, 11, 4370-4389.

27. Monsinjon, T.; Knigge, T. Proteomic applications in ecotoxicology. Proteomics 2007, 7, 2997-3009.

28. Campos, A.; Puerto, M.; Prieto, A.; Camean, A.; Almeida, A.M.; Coelho, A.V.; Vasconcelos, V. Protein extraction and two-dimensional gel electrophoresis of proteins in the marine mussel Mytilus galloprovincialis: An important tool for protein expression studies, food quality and safety assessment. J. Sci. Food Agric. 2013, 93, 1779-1787.

29. Rabilloud, T.; Chevallet, M.; Luche, S.; Lelong, C. Two-dimensional gel electrophoresis in proteomics: Past, present and future. J. Proteomics 2010, 73, 2064-2077.

30. Cannuel, R.; Beninger, P.G.; McCombie, H.; Boudry, P. Gill Development and its functional and evolutionary implications in the blue mussel Mytilus edulis (Bivalvia: Mytilidae). Biol. Bull. 2009, 217, 173-188.

31. Barker Jorgensen, C. A Hydromechanical Principle for Particle Retention in Mytilus edulis and Other Ciliary Suspension Feeders. Mar. Biol. 1981, 61, 277-282.

32. Bradford, M.M. A rapid and sensitive method for the quantitation of microgram quantities of protein utilizing the principle of protein-dye binding. Anal. Biochem. 1976, 72, 248-254.

33. Bonett, D.G. Confidence interval for a coefficient of quartile variation. Comput. Stat. Data Anal. 2006, 50, 2953-2957. 
34. Dejda, A.; Chan, P.; Seaborn, T.; Coquet, L.; Jouenne, T.; Fournier, A.; Vaudry, H.; Vaudry, D. Involvment of Stathmin 1 in the neurotrophic effects of PACAP in PC12 cells. J. Neurochem. 2010, 114, 1498-1510.

35. Shepard, J.L.; Olsson, B.; Tedengren, M.; Bradley, B.P. Protein expression signatures identified in Mytilus edulis exposed to PCBs, copper and salinity stress. Mar. Environ. Res. 2000, 50, 337-340.

36. Fields, P.A.; Zuzow, M.J.; Tomanek, L. Proteomic responses of blue mussel (Mytilus) congeners to temperature acclimation. J. Exp. Biol. 2012, 215, 1106-1116.

37. Dondero, F.; Negri, A.; Boatti, L.; Marsano, F.; Mignone, F.; Viarengo, A. Transcriptomic and proteomic effects of a neonicotinoid insecticide mixture in the marine mussel (Mytilus galloprovincialis, Lam.). Sci. Total Environ. 2010, 408, 3775-3786.

38. Leung, P.T.; Wang, Y.; Mak, S.S.; Ng, W.C.; Leung, K.M. Differential proteomic responses in hepatopancreas and adductor muscles of the green-lipped mussel Perna viridis to stresses induced by cadmium and hydrogen peroxide. Aquat. Toxicol. 2011, 105, 49-61.

39. Puerto, M.; Campos, A.; Prieto, A.; Camean, A.; de Almeida, A.M.; Coelho, A.V.; Vasconcelos, V. Differential protein expression in two bivalve species; Mytilus galloprovincialis and Corbicula fluminea; exposed to Cylindrospermopsis raciborskii cells. Aquat. Toxicol. 2011, 101, 109-116.

40. Gomes, T.; Araujo, O.; Pereira, R.; Almeida, A.C.; Cravo, A.; Bebianno, M.J. Genotoxicity of copper oxide and silver nanoparticles in the mussel Mytilus galloprovincialis. Mar. Environ. Res. 2013, 84, 51-59.

41. Wu, H.; Ji, C.; Wei, L.; Zhao, J.; Lu, H. Proteomic and metabolomic responses in hepatopancreas of Mytilus galloprovincialis challenged by Micrococcus luteus and Vibrio anguillarum. J. Proteomics 2013, 94, 54-67.

42. Wu, H.; Ji, C.; Wei, L.; Zhao, J. Evaluation of protein extraction protocols for 2DE in marine ecotoxicoproteomics. Proteomics 2013, 13, 3205-3210.

43. Kolli, S.; Zito, C.I.; Mossink, M.H.; Wiemer, E.A.; Bennett, A.M. The major vault protein is a novel substrate for the tyrosine phosphatase SHP-2 and scaffold protein in epidermal growth factor signaling. J. Biol. Chem. 2004, 279, 29374-29385.

44. Lin, G.; Brownsey, R.W.; MacLeod, K.M. Regulation of mitochondrial aconitase by phosphorylation in diabetic rat heart. Cell. Mol. Life Sci. 2009, 66, 919-932.

45. Muller, P.; Ruckova, E.; Halada, P.; Coates, P.J.; Hrstka, R.; Lane, D.P.; Vojtesek, B. C-Terminal phosphorylation of Hsp70 and Hsp90 regulates alternate binding to co-chaperones CHIP and HOP to determine cellular protein folding/degradation balances. Oncogene 2013, 32, 3101-3110.

46. Walker, R.P.; Leegood, R.C. Phosphorylation of phosphoenolpyruvate carboxykinase in plants: Studies in plants with $\mathrm{C} 4$ photosynthesis and Crassulacean acid metabolism and in germinating seeds. Biochem. J. 1996, 317, 653-658.

47. Petrak, J.; Ivanek, R.; Toman, O.; Cmejla, R.; Cmejlova, J.; Vyoral, D.; Zivny, J.; Vulpe, C.D. Deja vu in proteomics. A hit parade of repeatedly identified differentially expressed proteins. Proteomics 2008, 8, 1744-1749.

48. Evans, T.G.; Somero, G.N. Phosphorylation events catalyzed by major cell signaling proteins differ in response to thermal and osmotic stress among native (Mytilus californianus and Mytilus trossulus) and invasive (Mytilus galloprovincialis) species of mussels. Physiol. Biochem. Zool. 2010, 83, 984-996. 
49. Storey, K.B.; Storey, J.M. Heat schock proteins and hypometabolism: Adaptive strategy for protein preservation. Res. Rep. Biol. 2011, 2, 57-68.

50. McDonagh, B.; Tyther, R.; Sheehan, D. Carbonylation and glutathionylation of proteins in the blue mussel Mytilus edulis detected by proteomic analysis and Western blotting: Actin as a target for oxidative stress. Aquat. Toxicol. 2005, 73, 315-326.

51. Apraiz, I.; Mi, J.; Cristobal, S. Identification of proteomic signatures of exposure to marine pollutants in mussels (Mytilus edulis). Mol. Cell Proteomics 2006, 5, 1274-1285.

52. Company, R.; Torreblanca, A.; Cajaraville, M.; Bebianno, M.J.; Sheehan, D. Comparison of thiol subproteome of the vent mussel Bathymodiolus azoricus from different Mid-Atlantic Ridge vent sites. Sci. Total Environ. 2012, 437, 413-421.

53. Hu, W.; Culloty, S.; Darmody, G.; Lynch, S.; Davenport, J.; Ramirez-Garcia, S.; Dawson, K.A.; Lynch, I.; Blasco, J.; Sheehan, D. Toxicity of copper oxide nanoparticles in the blue mussel, Mytilus edulis: A redox proteomic investigation. Chemosphere 2014, 108, 289-299.

54. Schluter, H.; Apweiler, R.; Holzhutter, H.G.; Jungblut, P.R. Finding one's way in proteomics: A protein species nomenclature. Chem. Cent. J. 2009, 3, e11.

55. Lisitsa, A.; Moshkovskii, S.; Chernobrovkin, A.; Ponomarenko, E.; Archakov, A. Profiling proteoforms: Promising follow-up of proteomics for biomarker discovery. Expert Rev. Proteomics 2014, 11, 121-129.

56. Shepard, J.L.; Bradley, B.P. Protein expression signatures and lysosomal stability in Mytilus edulis exposed to graded copper concentrations. Mar. Environ. Res. 2000, 50, 457-463.

57. Lopez, J.L.; Mosquera, E.; Fuentes, J.; Marina, A.; Vlazquez, J.; Alvarez, G. Two-dimensional gel electrophoresis of Mytilus galloprovincialis: Differences in protein expression of intertidal and cultured mussels. Mar. Ecol. Progr. Ser. 2001, 224, 149-156.

58. Fuentes, J.; López, J.L.; Mosquera, E.; Vázquez, J.; Villalba, A.; Álvarez, G. Growth, mortality, pathological conditions and protein expression of Mytilus edulis and M. galloprovincialis crosses cultured in the Ría de Arousa (NW of Spain). Aquaculture 2002, 213, 233-251.

59. Mi, J.; Orbea, A.; Syme, N.; Ahmed, M.; Cajaraville, M.P.; Cristobal, S. Peroxisomal proteomics, a new tool for risk assessment of peroxisome proliferating pollutants in the marine environment. Proteomics 2005, 5, 3954-3965.

60. Amelina, H.; Apraiz, I.; Sun, W.; Cristobal, S. Proteomics-based method for the assessment of marine pollution using liquid chromatography coupled with two-dimensional electrophoresis. J. Proteome Res. 2007, 6, 2094-2104.

61. Jonsson, H.; Schiedek, D.; Grøsvik, B.E.; Goksøyr, A. Protein responses in blue mussels (Mytilus edulis) exposed to organic pollutants: A combined CYP-antibody/proteomic approach. Aquat. Toxicol. 2006, 78, S49-S56.

62. Apraiz, I.; Cajaraville, M.P.; Cristobal, S. Peroxisomal proteomics: Biomonitoring in mussels after the Prestige's oil spill. Mar. Pollut. Bull. 2009, 58, 1815-1826.

63. Diz, A.P.; Dudley, E.; MacDonald, B.W.; Pina, B.; Kenchington, E.L.; Zouros, E.; Skibinski, D.O. Genetic variation underlying protein expression in eggs of the marine mussel Mytilus edulis. Mol. Cell Proteomics 2009, 8, 132-144.

64. Diz, A.P.; Dudley, E.; Skibinski, D.O. Identification and characterization of highly expressed proteins in sperm cells of the marine mussel Mytilus edulis. Proteomics 2012, 12, 1949-1956. 
65. Schmidt, W.; Rainville, L.C.; McEneff, G.; Sheehan, D.; Quinn, B. A proteomic evaluation of the effects of the pharmaceuticals diclofenac and gemfibrozil on marine mussels (Mytilus spp.): Evidence for chronic sublethal effects on stress-response proteins. Drug Test. Anal. 2014, 6, 210-219.

66. Schwelberger, H.G.; Kang, H.A.; Hershey, J.W. Translation initiation factor eIF-5A expressed from either of two yeast genes or from human cDNA. Functional identity under aerobic and anaerobic conditions. J. Biol. Chem. 1993, 268, 14018-14025.

67. Borradaile, N.M.; Buhman, K.K.; Listenberger, L.L.; Magee, C.J.; Morimoto, E.T.; Ory, D.S.; Schaffer, J.E. A critical role for eukaryotic elongation factor 1A-1 in lipotoxic cell death. Mol. Biol. Cell 2006, 17, 770-778.

68. Merrick, W.C. Mechanism and regulation of eukaryotic protein synthesis. Microbiol. Rev. 1992, 56, 291-315.

69. Gonen, H.; Smith, C.E.; Siegel, N.R.; Kahana, C.; Merrick, W.C.; Chakraburtty, K.; Schwartz, A.L.; Ciechanover, A. Protein synthesis elongation factor EF-1 alpha is essential for ubiquitin-dependent degradation of certain $\mathrm{N}$ alpha-acetylated proteins and may be substituted for by the bacterial elongation factor EF-Tu. Proc. Natl. Acad. Sci. USA 1994, 91, 7648-7652.

70. Darbinian, N.; Gallia, G.L.; Kundu, M.; Shcherbik, N.; Tretiakova, A.; Giordano, A.; Khalili, K. Association of Pur alpha and E2F-1 suppresses transcriptional activity of E2F-1. Oncogene 1999, 18, 6398-6402.

71. Tanaka, H.; Matsumura, I.; Ezoe, S.; Satoh, Y.; Sakamaki, T.; Albanese, C.; Machii, T.; Pestell, R.G.; Kanakura, Y. E2F1 and c-Myc potentiate apoptosis through inhibition of NF-kappaB activity that facilitates MnSOD-mediated ROS elimination. Mol. Cell 2002, 9, 1017-1029.

72. Skorzewski, R.; Sliwinska, M.; Borys, D.; Sobieszek, A.; Moraczewska, J. Effect of actin C-terminal modification on tropomyosin isoforms binding and thin filament regulation. Biochim. Biophys. Acta 2009, 1794, 237-243.

73. Norrander, J.M.; deCathelineau, A.M.; Brown, J.A.; Porter, M.E.; Linck, R.W. The Rib43a protein is associated with forming the specialized protofilament ribbons of flagellar microtubules in Chlamydomonas. Mol. Biol. Cell 2000, 11, 201-215.

74. Sandoz, D.; Chailley, B.; Boisvieux-Ulrich, E.; Lemullois, M.; Laine, M.C.; Bautista-Harris, G. Organization and functions of cytoskeleton in metazoan ciliated cells. Biol. Cell 1988, 63, 183-193.

75. Brett, C.L.; Donowitz, M.; Rao, R. Evolutionary origins of eukaryotic sodium/proton exchangers. Am. J. Physiol. Cell Physiol. 2005, 288, C223-C239.

76. Wang, W.; Brautigan, D.L. Phosphatase inhibitor 2 promotes acetylation of tubulin in the primary cilium of human retinal epithelial cells. BMC Cell Biol. 2008, 9, e62.

77. Blond, D.M.; Whittam, R. The regulation of kidney respiration by sodium and potassium ions. Biochem. J. 1964, 92, 158-167.

78. Balaban, R.S.; Mandel, L.J.; Soltoff, S.P.; Storey, J.M. Coupling of active ion transport and aerobic respiratory rate in isolated renal tubules. Proc. Natl. Acad. Sci. USA 1980, 77, 447-451.

79. Ciechanover, A.; Heller, H.; Elias, S.; Haas, A.L.; Hershko, A. ATP-dependent conjugation of reticulocyte proteins with the polypeptide required for protein degradation. Proc. Natl. Acad. Sci. USA 1980, 77, 1365-1368.

80. Jiang, J.; Maes, E.G.; Taylor, A.B.; Wang, L.; Hinck, A.P.; Lafer, E.M.; Sousa, R. Structural basis of J cochaperone binding and regulation of Hsp70. Mol. Cell 2007, 28, 422-433. 
81. Livingstone, D.R. Origins and evolution of pathways of anaerobic metabolism in the animal kingdom. Amer. Zool. 1991, 31, 522-534.

82. Pereira, C.A.; Alonso, G.D.; Paveto, M.C.; Iribarren, A.; Cabanas, M.L.; Torres, H.N.; Flawia, M.M. Trypanosoma cruzi arginine kinase characterization and cloning. A novel energetic pathway in protozoan parasites. J. Biol. Chem. 2000, 275, 1495-1501.

83. Reddy, S.R.; Houmeida, A.; Benyamin, Y.; Roustan, C. Interaction in vitro of scallop muscle arginine kinase with filamentous actin. Eur. J. Biochem. 1992, 206, 251-257.

84. Bishop, S.H.; Ellis, L.L.; Burcham, J.M. Amino Acid Metabolism in Molluscs. In Metabolic Biochemistry and Molecular Biomechanics; Hochachka, P.W., Ed.; Academic Press: Waltham, MA, USA, 1983; pp. 243-327.

85. De Zwaan, A. Carbohydrate Catabolism in Bivalves. In Metabolic Biochemistry and Molecular Biomechanics; 1983 ed.; Hochachka, P.W., Ed.; Academic Press: Waltham, MA, USA, 1983; pp. 137-175.

86. Behrens, J.W.; Elias, J.P.; Taylor, H.H.; Weber, R.E. The archaeogastropod mollusc Haliotis iris: Tissue and blood metabolites and allosteric regulation of haemocyanin function. J. Exp. Biol. 2002, 205, 253-263.

87. Bradshaw, J.C.; Kumai, Y.; Perry, S.F. The effects of gill remodeling on transepithelial sodium fluxes and the distribution of presumptive sodium-transporting ionocytes in goldfish (Carassius auratus). J. Comp. Physiol. B 2012, 182, 351-366.

88. Wang, L.; Zhang, H.; Zhou, Z.; Siva, V.S.; Song, L. A C1q domain containing protein from scallop Chlamys farreri serving as pattern recognition receptor with heat-aggregated IgG binding activity. PLOS ONE 2012, 7, e43289.

89. Liu, H.H.; Xiang, L.X.; Shao, J.Z. A novel C1q-domain-containing (C1qDC) protein from Mytilus coruscus with the transcriptional analysis against marine pathogens and heavy metals. Dev. Comp. Immunol. 2014, 44, 70-75.

90. Moreira, R.; Balseiro, P.; Romero, A.; Dios, S.; Posada, D.; Novoa, B.; Figueras, A. Gene expression analysis of clams Ruditapes philippinarum and Ruditapes decussatus following bacterial infection yields molecular insights into pathogen resistance and immunity. Dev. Comp. Immunol. 2012, 36, $140-149$.

91. Gestal, C.; Costa, M.; Figueras, A.; Novoa, B. Analysis of differentially expressed genes in response to bacterial stimulation in hemocytes of the carpet-shell clam Ruditapes decussatus: Identification of new antimicrobial peptides. Gene 2007, 406, 134-143.

92. Livingstone, D.R. Cytochrome P-450 and oxidative metabolism in invertebrates. Biochem. Soc. Trans. 1990, 18, 15-19.

93. Ercal, N.; Gurer-Orhan, H.; Aykin-Burns, N. Toxic metals and oxidative stress part I: Mechanisms involved in metal-induced oxidative damage. Curr. Top. Med. Chem. 2001, 1, 529-539.

94. Allen, R.G.; Tresini, M. Oxidative stress and gene regulation. Free Radic. Biol. Med. 2000, 28, 463-499.

95. Khessiba, A.; Romeo, M.; Aissa, P. Effects of some environmental parameters on catalase activity measured in the mussel (Mytilus galloprovincialis) exposed to lindane. Environ. Pollut. 2005, 133, $275-281$. 
96. Regoli, F.; Gorbi, S.; Fattorini, D.; Tedesco, S.; Notti, A.; Machella, N.; Bocchetti, R.; Benedetti, M.; Piva, F. Use of the land snail Helix aspersa as sentinel organism for monitoring ecotoxicologic effects of urban pollution: An integrated approach. Environ. Health Perspect. 2006, 114, 63-69.

97. Letendre, J.; Chouquet, B.; Manduzio, H.; Marin, M.; Bultelle, F.; Leboulenger, F.; Durand, F. Tidal height influences the levels of enzymatic antioxidant defences in Mytilus edulis. Mar. Environ. Res. 2009, 67, 69-74.

98. Ross, S.J.; Findlay, V.J.; Malakasi, P.; Morgan, B.A. Thioredoxin peroxidase is required for the transcriptional response to oxidative stress in budding yeast. Mol. Biol. Cell 2000, 11, 2631-2642.

99. Fitzpatrick, P.J.; Sheehan, D. Separation of multiple forms of glutathione S-transferase from the blue mussel, Mytilus edulis. Xenobiotica 1993, 23, 851-861.

100. Sheehan, D.; Meade, G.; Foley, V.M.; Dowd, C.A. Structure, function and evolution of glutathione transferases: Implications for classification of non-mammalian members of an ancient enzyme superfamily. Biochem. J. 2001, 360, 1-16.

101. Young, J.C.; Agashe, V.R.; Siegers, K.; Hartl, F.U. Pathways of chaperone-mediated protein folding in the cytosol. Nat. Rev. Mol. Cell Biol. 2004, 5, 781-791.

102. Mayer, M.P.; Bukau, B. Hsp70 chaperones: Cellular functions and molecular mechanism. Cell. Mol. Life Sci. 2005, 62, 670-684.

103. Richter, K.; Haslbeck, M.; Buchner, J. The heat shock response: Life on the verge of death. Mol. Cell 2010, 40, 253-266.

104. Hilton, G.R.; Lioe, H.; Stengel, F.; Baldwin, A.J.; Benesch, J.L. Small heat-shock proteins: Paramedics of the cell. Top. Curr. Chem. 2013, 328, 69-98.

105. Garrido, C.; Paul, C.; Seigneuric, R.; Kampinga, H.H. The small heat shock proteins family: The long forgotten chaperones. Int. J. Biochem. Cell Biol. 2012, 44, 1588-1592.

106. Mogk, A.; Deuerling, E.; Vorderwulbecke, S.; Vierling, E.; Bukau, B. Small heat shock proteins, $\mathrm{ClpB}$ and the DnaK system form a functional triade in reversing protein aggregation. Mol. Microbiol. 2003, 50, 585-595.

107. Tissieres, A.; Mitchell, H.K.; Tracy, U.M. Protein synthesis in salivary glands of Drosophila melanogaster: Relation to chromosome puffs. J. Mol. Biol. 1974, 84, 389-398.

108. Young, J.T.; Heikkila, J.J. Proteasome inhibition induces hsp30 and hsp 70 gene expression as well as the acquisition of thermotolerance in Xenopus laevis A6 cells. Cell Stress Chaperones 2010, 15, 323-334.

109. Feder, M.E.; Hofmann, G.E. Heat-shock proteins, molecular chaperones, and the stress response: Evolutionary and ecological physiology. Annu. Rev. Physiol. 1999, 61, 243-282.

110. Sørensen, J.G.; Kristensen, T.N.; Loeschcke, V. The evolutionary and ecological role of heat shock proteins. Ecol. Lett. 2003, 6, 1025-1037.

111. Clark, M.S.; Peck, L.S. Triggers of the HSP70 stress response: Environmental responses and laboratory manipulation in an Antarctic marine invertebrate (Nacella concinna). Cell Stress Chaperones 2009, 14, 649-660.

112. Cottin, D.; Shillito, B.; Chertemps, T.; Tanguy, A.; Leger, N.; Ravaux, J. Identification of differentially expressed genes in the hydrothermal vent shrimp Rimicaris exoculata exposed to heat stress. Mar. Genomics 2010, 3, 71-78. 
113. Knigge, T.; Bachmann, L.; Kohler, H.R. An intron-containing, heat-inducible stress-70 gene in the millipede Tachypodoiulus niger (Julidae, Diplopoda). Cell Stress Chaperones 2014, 19, 741-747.

114. Carpentier, S. KU Leuven, Division of Biosystems: Leuven, Belgium. Personal communication, 2014.

115. Meiri, D.; Breiman, A. Arabidopsis ROF1 (FKBP62) modulates thermotolerance by interacting with HSP90.1 and affecting the accumulation of HsfA2-regulated sHSPs. Plant J. 2009, 59, 387-399.

116. Xu, Q.; Metzler, B.; Jahangiri, M.; Mandal, K. Molecular chaperones and heat shock proteins in atherosclerosis. Am. J. Physiol. Heart Circ. Physiol. 2012, 302, H506-H514.

117. Kohler, H.R.; Lazzara, R.; Dittbrenner, N.; Capowiez, Y.; Mazzia, C.; Triebskorn, R. Snail phenotypic variation and stress proteins: Do different heat response strategies contribute to Waddington's widget in field populations? J. Exp. Zool. B Mol. Dev. Evol. 2009, 312, 136-147.

118. Leach, M.D.; Budge, S.; Walker, L.; Munro, C.; Cowen, L.E.; Brown, A.J. Hsp90 orchestrates transcriptional regulation by Hsf1 and cell wall remodelling by MAPK signalling during thermal adaptation in a pathogenic yeast. PLoS Pathog. 2012, 8, e1003069.

119. Inglis, P.N.; Boroevich, K.A.; Leroux, M.R. Piecing together a ciliome. Trends Genet. 2006, 22, 491-500.

120. Hershko, A.; Ciechanover, A.; Heller, H.; Haas, A.L.; Rose, I.A. Proposed role of ATP in protein breakdown: Conjugation of protein with multiple chains of the polypeptide of ATP-dependent proteolysis. Proc. Natl. Acad. Sci. USA 1980, 77, 1783-1786.

121. Gotze, S.; Bose, A.; Abele, D.; Sokolova, I.M.; Saborowski, R. Pitfalls in invertebrate proteasome assays. J. Exp. Biol. 2013, 216, 1351-1354.

122. Varotto, L.; Domeneghetti, S.; Rosani, U.; Manfrin, C.; Cajaraville, M.P.; Raccanelli, S.; Pallavicini, A.; Venier, P. DNA damage and transcriptional changes in the gills of mytilus galloprovincialis exposed to nanomolar doses of combined metal salts ( $\mathrm{Cd}, \mathrm{Cu}, \mathrm{Hg})$. PLoS One 2013, 8, e54602.

123. Tanguy, M.; McKenna, P.; Gauthier-Clerc, S.; Pellerin, J.; Danger, J.M.; Siah, A. Functional and molecular responses in Mytilus edulis hemocytes exposed to bacteria, Vibrio splendidus. Dev. Comp. Immunol. 2013, 39, 419-429.

124. Dupont, S.; Mamidi, A.; Cordenonsi, M.; Montagner, M.; Zacchigna, L.; Adorno, M.; Martello, G.; Stinchfield, M.J.; Soligo, S.; Morsut, L.; et al. FAM/USP9x, a deubiquitinating enzyme essential for TGFbeta signaling, controls Smad4 monoubiquitination. Cell 2009, 136, 123-135.

125. Kulkarni, A.; Oza, J.; Yao, M.; Sohail, H.; Ginjala, V.; Tomas-Loba, A.; Horejsi, Z.; Tan, A.R.; Boulton, S.J.; Ganesan, S. Tripartite Motif-containing 33 (TRIM33) protein functions in the poly(ADP-ribose) polymerase (PARP)-dependent DNA damage response through interaction with Amplified in Liver Cancer 1 (ALC1) protein. J. Biol. Chem. 2013, 288, 32357-32369.

126. Chondrogianni, N.; Petropoulos, I.; Grimm, S.; Georgila, K.; Catalgol, B.; Friguet, B.; Grune, T.; Gonos, E.S. Protein damage, repair and proteolysis. Mol. Aspects Med. 2014, 35, 1-71.

127. Tanaka, K. The proteasome: From basic mechanisms to emerging roles. Keio J. Med. 2013, 62, $1-12$.

128. Groll, M.; Bajorek, M.; Kohler, A.; Moroder, L.; Rubin, D.M.; Huber, R.; Glickman, M.H.; Finley, D. A gated channel into the proteasome core particle. Nat. Struct. Biol. 2000, 7, 1062-1067. 
129. Jager, S.; Groll, M.; Huber, R.; Wolf, D.H.; Heinemeyer, W. Proteasome beta-type subunits: Unequal roles of propeptides in core particle maturation and a hierarchy of active site function. J. Mol. Biol. 1999, 291, 997-1013.

130. Kunjappu, M.J.; Hochstrasser, M. Assembly of the 20S proteasome. Biochim. Biophys. Acta 2014, 1843, 2-12.

131. Lee, M.J.; Lee, B.H.; Hanna, J.; King, R.W.; Finley, D. Trimming of ubiquitin chains by proteasome-associated deubiquitinating enzymes. Mol. Cell Proteomics 2011, 10, R110.003871.

132. Butler, L.R.; Densham, R.M.; Jia, J.; Garvin, A.J.; Stone, H.R.; Shah, V.; Weekes, D.; Festy, F.; Beesley, J.; Morris, J.R. The proteasomal de-ubiquitinating enzyme POH1 promotes the double-strand DNA break response. EMBO J. 2012, 31, 3918-3934.

133. Lam, Y.A.; Lawson, T.G.; Velayutham, M.; Zweier, J.L.; Pickart, C.M. A proteasomal ATPase subunit recognizes the polyubiquitin degradation signal. Nature 2002, 416, 763-767.

134. Shanmuganathan, A.; Avery, S.V.; Willetts, S.A.; Houghton, J.E. Copper-induced oxidative stress in Saccharomyces cerevisiae targets enzymes of the glycolytic pathway. FEBS Lett. 2004, 556, 253-259.

135. Santos, P.M.; Benndorf, D.; Sa-Correia, I. Insights into Pseudomonas putida KT2440 response to phenol-induced stress by quantitative proteomics. Proteomics 2004, 4, 2640-2652.

136. Kultz, D. Evolution of the cellular stress proteome: From monophyletic origin to ubiquitous function. J. Exp. Biol. 2003, 206, 3119-3124.

137. McDonagh, B.; Sheehan, D. Redox proteomics in the blue mussel Mytilus edulis: Carbonylation is not a prerequisitefor ubiquination in acute free radical-mediated oxidative stress. Aquat. Toxicol. 2006, 79, 325-333.

138. McDonagh, B.; Sheehan, D. Effect of oxidative stress on protein thiols in the blue mussel Mytilus edulis: Proteomic identification of target proteins. Proteomics 2007, 7, 3395-3403.

(C) 2015 by the authors; licensee MDPI, Basel, Switzerland. This article is an open access article distributed under the terms and conditions of the Creative Commons Attribution license (http://creativecommons.org/licenses/by/4.0/). 